\title{
«UN DELS SUPTILS MAESTRES DE LA SUA ART QUI SIEN EN NOSTRA SENYORIA»: CONSOLÍ BLANCH D'ESTRASBURG, UN ARGENTER ALEMANY A LA CORONA D'ARAGÓ $(1372-1401)^{1}$
}

\author{
ANNA MOLINA I CASTELLÀ \\ Universitat de Barcelona
}

SUMARI

1. Consoli Blanch, argenter d’Estrasburg.- 2. Segells per a la família reial aragonesa.- 3. Una creu d'or per a l'arquebisbe de Saragossa.- 4. De nou, la vinculació amb la cort aragonesa.- 5. Paraules de reconeixement vers un artífex.- 6 . Una nova clientela: la Corona navarresa.- 7. L'argenter, al servei de Martí l'Humà.- Apèndix.

Lluny de les etapes artístiques més recents en què és possible reconstruir totalment les vides dels artistes, conèixer-ne la formació, les influències, els períodes de llur producció o els viatges per ampliar horitzons, l'estudi dels artesans medievals manté el suspens de no saber gran cosa del seu esdevenir vital. Notícies isolades de caràcter particular, o referents a algunes obres, les quals en comptades ocasions s'han conservat, serveixen de pauta per esbossar els perfils d'uns personatges importants que sovint es troben en la penombra. En el camp de la recerca sobre l'argenteria medieval catalana, hi ha poques monografies dedicades a cadascun d'aquests

'En record i agraïment a Regina Sainz de la Maza i Lasoli, la persona que em va fer l'arxiu acollidor.

"Anuario de l:studies Medievales". 29 (1999) 
mestres que facin ús de les dades trobades i de les obres preservades per traçar llur trajectòria. La intenció que persegueix el present article és resseguir les diferents informacions que permetin aproximar-nos a un dels principals orfebres que treballaren a la Corona d'Aragó a finals del segle XIV: Consolí Blanch d'Estrasburg².

Diversos aspectes fan el personatge atractiu. D'una banda, la seva procedència; de l'altra, la vinculació amb la cort aragonesa, ja des de la dada més antiga de la qual se'n té coneixement; en tercer lloc, el seu probable establiment prolongat o definitiu a la ciutat de Saragossa; després, els serveis desenvolupats per a diferents institucions peninsulars $\mathrm{i}$, per últim, la desaparició de les obres documentades que sorgiren del seu enginy. Des de les primeres notícies localitzades s'insinua com un artesà ben format i versàtil en l'art de fer segells, tal i com ho demostren els encàrrecs efectuats i els apel-latius amb què es rubrica sovint el seu nom: mestre de fer segells o mestre de segells. Tot i que amb posterioritat la documentació posa de manifest que també realitzà altres obres de tipologies i funcions diverses, els segells constituïren l'ocupació prioritària al llarg de la seva vida professional.

Fins ara, tan sols s'han localitzat dos argenters alemanys a Barcelona actius al segle XIV: Colí de Namur i Consolí Blanch. En canvi, a partir de 1400 n'apareixen altres tres, com són Joan Olxamar, Teodoric de la Vort i Hans Tramer ${ }^{3}$, procedents de les viles o ciutats alemanyes d'Elena -oriundus ville de Elena in Alamannia-, S'Hertogensbosch (Bois le Duc)

\footnotetext{
${ }^{2}$ El present treball forma part d'una investigació en curs en motiu de la tesi doctoral, mercès a la "Beca de Formació en la Recerca i la Docència de la Universitat de Barcelona". Al mateix temps s'emmarca en el projecte de recerca PS 94-0245 (DGICYT, Ministerio de Educación y Ciencia), que sota el títol "La corte de Martín el Humano y el alcance internacional de Barcelona como centro artístico (ca. 1400)" es duu a terme en el Departament d'Història de l'Art de la Universitat de Barcelona.

${ }^{3}$ Algunes notícies relatives a Colí de Namur, Consoli Blanch, Teodoric de la Vort i Hans Tramer poden consultar-se a N. DE DALMASES, Orfebreria Catalana Medieval: Barcelona 13001500. Aproximació a l'estudi. Barcelona, Institut d'Estudis Catalans, 1992. vol. II, pp. 106. 36, 152 i 141-142, respectivament; en referència a Consolí Blanch i Joan Olxamar, vegeu M. MITJÀ, Dificultades de la industria y comercio alemanes para abrirse paso en Barcelona hasta 1410, "Sonderdruck aus Spanische Forschungen der Görresgesellschaft. Gesammelte Aufsätze zur Kulturgeschichte Spaniens", 13 (1958), pp. 188 i 222, respectivament; altres dades sobre Colí de Namur i Consolí Blanch es troben a A. MOLINA I CASTELLÀ, "L'argenter de Casa del Senyor Rei»: una distinció laboral de prestigi, dins: "Congrés L'artista-artesà medieval a la Corona d'Aragó" (Lleida, 1998). En premsa.
} 
- oriundus civitate Boscoducis, Imperii Alamannie - i Constança - nadiu de Constança de l'Imperi de Alamanya-, respectivament ${ }^{4}$.

L'historiadora Marina Mitjà intentà donar una explicació de la presència d'alemanys a Barcelona $\mathrm{i}$ arribà a la conclusió que no es tractà d'una onada germànica vers la ciutat comtal, sinó d'interessos individuals $i$ de trasllats particulars que coincidiren en una mateixa població. Tot i així, M. Mitjà pensa que la majoria dels alemanys documentats a partir dels anys 70 del segle XIV i fins al final de la primera dècada del 1400, gairebé tots procedents de la Renània, es veieren arrossegats per un fort corrent migratori d'artesans franco-flamencs al seu pas per aquesta zona ${ }^{5}$. Efectivament, la presència a Barcelona d'oriünds de ciutats com Gant, Malines, Bruges, Brussel-les, Chalons o Verdun, amb una forta relació entre tots ells i alhora amb els renans una vegada establerts a Barcelona, acredita de ple aquesta observación.

${ }^{4}$ Recordem que en l'actualitat Estrasburg és una ciutat francesa. fronterera amb Alemanya, i que Namur pertany a Bèlgica i S'Hertogensbosch als Països Baixos. Intentant situar geogràficament l'esmentada vila alemanya d'Elena, hem trobat una localitat homònima situada just a sota de Gant, a l'actual Bèlgica. Cal precisar que en l'època en què es situa el present estudi, la denominació de l'Imperi Germànic o d'Alemanya, expressada des de fora de la zona geogràtica al-ludida, s'utilitzava com a genèric d'una gran àrea que comprenia el mateix Imperi i tota la zona nord-septentrional de l'Europa del moment. Vegeu J. GARRIGA, De noms dits a noms escrits: una hipòtesi sobre l'antropònim del pintor "Aine Bru". "Miscel-lània Oriol Martorell" (X. Aviñoa, ed.). Barcelona, Publicacions de la Universitat de Barcelona, 1998, pp. 267-279. esp. 275. D'altra banda, a la cort del Cerimoniós hi trobem d'altres personatges procedents d'Alemanya, com per exemple els ministrers Daniel de Bruyn, Johan de Constança i Huynqui d'Estrasburg que apareixen documentats durant la dècada dels anys vuitanta (ACA, Cancelleria, reg. 1283. fol. XXVII r.). o Renaqui d'Alamanya, ajudant del sastre de l'Infant En Joan, documentat d'ençà dels primers anys de la dècada dels setanta (ACA, RP. reg. 590. fol. LXXXVI r.)

${ }^{5}$ Vegeu M. MiTjà. ob. cit., pp. 188-228. Aquest estudi prova que l'arribada a Barcelona d'alemanys esdevingué més aviat del que hom havia cregut. D'altra banda, no és fortuït que la majoria d'alemanys documentats per M. Mitjà provinguin de la Renània, en tant que aquesta regió i la de l'Alemanya Meridional foren les que concentraren el poder econòmic de l'Imperi. Vegeu H. KellenbenZ, Las relaciones entre España y Alemania meridional alrededor de 1500 , "Anuario de Estudios Medievales", 10 (1980), pp. 545-554, esp. 547 i 548.

"Amb el mateix argument podria explicar-se també l'arribada massiva a la ciutat d'argenters procedents de París, de l'Alta Alvèrnia (Sant Flor i Lanjac) i de la Baixa Alvèrnia (Clarmont Ferrand i zona del Puei de Doma), especialment en el tombant de segle, entre els anys 1399 i 1400. Alhora, la pertinença a un mateix ofici i les quantioses notícies relatives a la seva producció $\mathrm{i}$ als seus tractes personals $\mathrm{i}$ comercials, permeten copsar el grau d'integració dels argenters francesos al sector orfebrístic barceloní. Un bon exemple n’és el cas dels germans Vidal i Barald Manxut (o Moxuc), argenters $\mathrm{i}$ ciutadans de Barcelona $\mathrm{i}$ alhora fills de Vidal Manxut, lapidari de Lanjac d'Alvèrnia. els quals tenien el seu taller al carrer de la Mar de Barcelona. Aquesta casa o taller els l'havia deixat en herència Berenguer Tió, argenter de Barcelona. Vegeu aquestes noticies a N. DE DALMASES, ol). cit., pp. 94-95 i 104 (hi ha dues entrades dedicades al mateix personatge, segons Manxut i Moxuc). Recentment, Albert Cubeles i Bonet, a qui agraeixo la gentilesa de cedir-me la informació, ha localitzat la concessió de la 
L'assentament de colònies estrangeres a Barcelona no és una novetat del tres-cents, sinó que es pot documentar des del segle XII a partir de les primeres notícies escrites relatives a les activitats comercials desenvolupades. Tot i la situació fluctuant que patí l'economia aragonesa des de la segona meitat del segle XIV - alguns historiadors parlen de crisi a partir de 1380 fins a finals del segon terç del segle XV, amb esdeveniments difícils de combatre com la Guerra dels Cent Anys a Occident o els fets de Constantinoble amb l'avançada turca a Orient ${ }^{7}-$, és indubtable que el moviment comercial que dominà Barcelona al llarg d'aquest període fou motiu de prosperitat especialment a partir de l'exportació de productes manufacturats, sobretot la llana, i del comerç amb les espècies, en connexió constant, via terrestre i marítima, amb les principals ciutats europees i mediterrànies ${ }^{8}$. L'àrea portuària fou solcada per naus genoveses, venecianes, mallorquines,

ciutadania a Vidal i Barald Moxuc en data del 21 de març de 1401 (Arxiu Històric de la Ciutat de Barcelona, "Miscel-lània Consellers-Informacions de Ciutadania", C-V3, 1395-1420). La integració de Vidal Moxuc, i fins i tot la seva bona consideració com a artesà, poden deduir-se de l'encàrrec rebut per part del Consell de Cent d'uns guarniments d'argent per a una terraça o gerra $\mathrm{i}$ un pitxer, ambdues peces de cristall, per tal de ser regalades a la reina Maria de Luna en visitar la ciutat per primera vegada com a sobirana. El 28 de juny de 1400 cobrà 57 lliures 4 sous pels treballs realitzats. Vegeu N. DE DALMASES, ob. cit., pp. 104 i 225, doc. 103.

${ }^{7}$ Vegeu C. CARRÈRE, Barcelone centre économique à l'époque des difficultés. 1380-1462, París-La Haye, Mouton \& Co, 1967 (trad. al català a Barcelona, Curial, 1977); M. DEL TREPPO, I mercanti catalani e' l'espansione della corona aragonese nel secolo XV. Napoli, L’Arte Tipográfica, 1967 (trad. al català a Barcelona, Curial, 1976). Més ponderat és el plantejament de la situació econòmica i comercial de la Corona d'Aragó que fá C. BATLLE 1 GALLART a L'expansió baixmedieval segles XIII-XV, dins História de Catalunya (Pierre Vilar. dir.), Barcelona, Ed. 62, 1988, vol. II, pp. 287-326.

${ }^{8}$ Segons H. Kellenbenz "el comercio de larga distancia [de Alemania Meridional] se expandió a partir de la segunda mitad del siglo XIII hacia las diversas partes de Europa (...). Bastante pronto los mercaderes alemanes dirigieron su atención a los países del otro lado de los Pirineos. Ya en tiempos de los Hohenstaufen existian ciertas relaciones que se extendieron hasta Andalucía, pero no sería antes de la decadencia de las ferias de la Champaña que el intercambio directo se intensificase (...). Es menester ver el comercio español de los alemanes en conexión con sus actividades en Francia. El mercado del azafrán, con centros como Lyon y Toulouse. tenía en Aragón su continuación al sur de los Pirineos (...). Desde esta época [1372], el rincón nordeste de España, con los reinos de Aragón y Valencia, Cataluña y el Rosellón francés, formó una región de creciente importancia para los negocios de exportación e importación de los alemanes meridionales". Vegeu H. KellenBENZ, ob. cit.. p. 547 i 548 . L'any 1406 es documenta a Barcelona l'existència d'una societat comercial, anomenada Ravensburger Gesellschaft, dirigida per Jos Humpis i Rudolf Mötteli de Ravensburg i Lutfried Muntprat de Constança, que exportava corall i safrà lleidatà vers la Germània, alhora que bàsicament importaven des d'allí teles de Constança cap a la Península Ibèrica. Vegeu M. MıTu̇̇, ob. cit. . pp. 202-204. Al llarg del segle XV els alemanys tingueren una presència creixent al regne de València. Vegeu J. Hinojosa Montalvo, Mercaderes alemanes en la Valencia del siglo XV: la "Gran Compañia" de Ravensburg, "Anuario de Estudios Medievales", 17 (1987). pp. 455468 . 
valencianes i barcelonines que des dels seus centres d'origen no només es dirigien al Pròxim i Llunyà Orient $\mathrm{i}$ al Nord d'Àfrica, sinó també a l'Atlàntic i a la Mar del Nord, on Londres i Bruges exercien de centres d'intercanvi entre els productes mediterranis, nòrdics i bàltics ${ }^{9}$. Aquest moviment frenètic intensificà els desplaçaments i l'establiment a la ciutat de mercaders, factors $i$ artesans, els quals hi trobaven l'acollida i la facilitat necessàries per tal d'instal-lar-s'hi i desenvolupar el seus negocis i activitats. Tanmateix, els privilegis concedits pel rei als estrangers havien de conviure amb les queixes dels súbdits, que es veien amenaçats per la competència d'unes infrastructures forànies més potents, i amb els interessos del propi monarca $^{10}$.

\section{CONSOlí Blanch, ARGENTER D'ESTRASBURG}

L'any 1915, Ferran de Sagarra donava a conèixer la figura de Consolí Blanch, mestre de fer segells, i el documentava des del 1373 fins al 1400 en el cercle de la família reial aragonesa. Més tard, les nombroses aportacions de M. Serrano Sanz i J.R. Castro engruixiren notablement el corpus de F. de Sagarra i donaren una nova dimensió al personatge, mentre

${ }^{9}$ La bibliografia sobre el tema és extensíssima. Entre moltes d'altres obres, vegeu: A. DE CAPMANY I DE MONPALAU, Memorias históricas sobre la marina, comercio y artes de la antigua ciudad de Barcelona. Barcelona. Cámara del Comercio y Navegación de Barcelona, 1962, 3 vols. (ed. orig. Barcelona, Junta de Comerç, 1779-1792); J. AINAUD DE LASARTE, Francesco de Marco Datini y sus relaciones econòmicas y culturales hispánicas, MadridBarcelona, 1957 (tesi doctoral mecanografiada, non vidit); F. SEvillano Colom. De Venecia a Flandes (Vía Mallorca y Portugal, siglo XIV), "Boletín de la Sociedad Arqueológica Luliana", LXXXIV (1968), pp. 1-33: C. BATLLE I GALLART, Els francesos a la Corona d'Aragó,

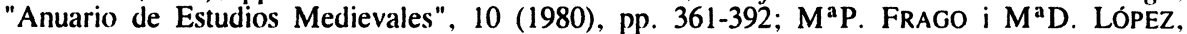
Barcelona i el comerç mediterrani i atlàntic a partir de les llicències de navegació (1400-1410), dins: XIII Congrés d'Història de la Corona d'Aragó. Comunicacions III (Palma de Mallorca, 1987) Palma de Mallorca, Institut d'Estudis Baleàrics, 1990, pp. 171-184; D. PIFARRÉ TORRES, Comunicació: noves dades sobre la navegació catalana cap a Flandes a la fi del segle XIV, Ibídem, pp. 227-235.

${ }^{10}$ Des d'aquesta perspectiva cal entendre especialment el cas dels italians, els quals foren expulsats del territori aragonès en múltiples ocasions, per tornar a ser acceptats seguidament, mitjançant la protecció de guiatges atorgats pel sobirà. Vegeu $M^{\mathrm{a}} \mathrm{T}$. FERRER I MALLOL, Els italians a terres catalanes (segles XII-XV), "Anuario de Estudios Medievales", 10 (1980), pp. 393-467. El 15 de gener de 1410, a instancia dels principals centres comercials de la Corona, Martí l'Humà ordenà que tots els mercaders que es trobessin o que arribessin per endavant al territori aragonès, fossin tractats com qualsevol altre súbdit $i$ que es sotmetessin als mateixos drets i deures. Vegeu J.P. MARTí I J. LlopIS, Constitucions de Cathalunya, Barcelona, 1704, p. 66 (non vidit) 
que A. Rubió i Lluch, F. Mendoza, A. López de Meneses, M. Mitjà i J.Ma Madurell i Marimón també hi contribuïren, tot i que més puntualment" ${ }^{11} \mathrm{La}$ revisió de totes aquestes notícies i la voluntat de posar-les en relació amb les que en ocasió d'investigacions inèdites més recents s'han anat descobrint, ens mouen a perfilar una trajectòria poc o parcialment coneguda ${ }^{12}$. Els documents relatius a l'argenter estrasburguès que fins ara s'han exhumat arriben a quaranta-dos i apareixen força seguits en el temps. Des del 13 d'octubre de 1372 i fins als primers mesos de 1401 , només dos buits documentals ens deixen momentàniament a les fosques: del 21 de juny de 1374 al juliol de 1378 i del 21 d'abril de 1386 al 7 d'abril de 1397. Aquestes llacunes informatives coincideixen amb un possible trasllat de Barcelona a Saragossa, la primera, i amb un suposat període d'intermitència de la documentació navarresa, la segona.

Procedent com ja s'ha esmentat de l'aleshores ciutat alemanya d'Estrasburg, dada que s'assenyala en els primers documents i que anys més tard esporàdicament es tornarà a especificar, Blanch és anomenat argenter

\footnotetext{
"Vegeu F. DE SAGARRA, Sigillografia catalana, Barcelona, Institut d'Estudis Catalans, 1915, vol. I; M. SERRANo SANZ, Documentos relativos a la pintura en Aragón durante los siglos XIV y XV, “Revista de Archivos, Bibliotecas y Museos”. 35 (1916), 409-421; A. RUBIó 1 LLUCH, Documents per l'Història de la Cultura Catalana Mig-eval, Barcelona, Institut d'Estudis Catalans, vol. II, 1921; F. MEndoza, Los plateros de Carlos el Noble, rey de Navarra. 1925 (non vidit); J.R. CASTRO, Catálogo del Archivo General. Sección de Comptos. Documentos, Pamplona, Edit. Aramburu, 1952-64: A. LÓPEZ DE MENESES, Florilegio documental del reinado de Pedro IV de Aragón. "Cuadernos de Historia de España". XVIII. 1952; A. LóPEZ De MENESES, Documentos culturales de Pedro el Ceremonioso, "Estudios de Edad Media en la Corona de Aragón", V, 1955; M. MITJȦ, ob. cit.; J.M ${ }^{a}$ MADURELL 1 MARIMÓn, Documents culturals medievals (1307-1485), "Boletín de la Real Academia de Buenas Letras de Barcelona”, XXXVIII (1979-1982). L'existència de la documentació saragossana relativa a Consolí la vàrem conèixer a través del treball de J.F. ESTEBAN LORENTE, La platería zaragozana en los siglos XIV y XV, "Homenaje a Don José María Lacarra de Miguel en su jubilación del profesorado", Saragossa, 1977, vol. III, pp. 331-343. El mateix cas succeí amb les notícies navarreses, que descobrírem mercès a la tesi doctoral publicada de $J$. Martínez DE AgUiRRe, Arte y monarquía en Navarra, 1328-1425, Pamplona, Gobierno de Navarra, 1987. Les diferents cotes documentals i bibliogràfiques seran especificades a mesura que s'al-ludeixi a cadascuna de les informacions en qüestió, referenciant tan sols l'autor que les donà a conèixer per primera vegada $i$ evitant, així, les publicacions que es limiten a recollir-les textualment.

1'La major part d'aquestes dades inèdites es troben a la nostra tesi de llicenciatura que, sota el títol L'orfebreria de Pere III el Cerimoniós a partir dels Llibres del Reial Patrimoni (13361387), fou presentada al Departament d'Història de l'Árt de la Universitat de Barcelona l'octubre de 1996. Les noticies que escapen a la cronologia referenciada en la tesina pertanyen a la recerca que estic duent a terme en motiu de la tesi doctoral.
} 
de Barcelona a partir del desembre de $1373^{13}$. El 5 de juliol de 1378 Pere el Cerimoniós ordenà a Bernat de Bonastre, protonotari reial, que portés ràpidament el segell de la majestat $\mathrm{i}$ el comú que l'any anterior havia començat a fer Cossolito i que estaven inacabats. Per aquest motiu, el monarca manà a l'argenter, el qual es trobava a Saragossa, que anés tan aviat com fos possible a la cort de Barcelona per tal d'enllestir-los ${ }^{14}$. Si hom posa aquest manament en relació amb les notícies que cronològicament el segueixen - que el situen a la capital aragonesa treballant per a l'arquebisbe-, hom tendeix a creure que Consolí s'hi instal-là de manera més o menys perllongada d'ençà de l'estiu de 1378. Les rúbriques argenter $i$ habitant de la ciutat de Saragossa que apareixen en els documents saragossans ho confirmen ${ }^{15}$. A partir d'aquest període, del qual només en coneixem la seva producció al servei de l'arquebisbe Lope Fernández de Luna, Consolí no tornarà a identificar-se com a argenter de Barcelona i fora de la documentació saragossana, tampoc ho serà com a habitant de Saragossa, sinó com a argenter d'Estrasburg.

\section{SEgells PER a la família Reial aRAgonesa}

Com s'ha dit, les primeres notícies el situen a Barcelona al servei de la cort del Cerimoniós. El 13 d'octubre de 1372, Consolí Blanch, mestre de

\footnotetext{
${ }^{13} \mathrm{El}$ caràcter bàsicament ecònomic dels suports arxivístics on es localitza aquest tipus d'informació, amb dades molt sintètiques i esquemes diplomàtics repetitius en funció de les característiques de la font, no permet aclarir si pel fet que Consolí Blanch sigui reconegut con a argenter de Barcelona, hom pot suposar que era ciutadà de Barcelona. En tot cas. en cap dels documents exhumats s'explicita que Blanch hagués rebut la ciutadania barcelonina.

${ }^{14}$ Vegeu F. DE SAGARRA, ob. cit., p. 84, doc. LXVII.

${ }^{15} \mathrm{La}$ consideració d'habitant, qualificació que depenia del fet de disposar de domicili constant a la ciutat, era un dels primers aspectes a tenir en compte a l'hora d'aconseguir la carta de ciutadanatge. A Barcelona, per exemple, tenia dret a ser ciutadà tot aquell que com a mínim fés un any $i$ un dia que residia a la ciutat $i$ que "posseint un domicili a Barcelona (llogat o en plena propietat), viu dels seus propis recursos, paga els impostos urbans i satisfà les obligacions de ver ciutadà, tal com la compra del blat municipal quan tenen lloc els repartiments oficials, el treball (en persona o per mitjà d'un tercer) a la construcció de les muralles o l'assitència als oficis de la seva parròquia els dies de festa". Per tal de concedir el títol de ciutadà, en els casos dubtosos "hom procedeix a una enquesta interrogant als veïns, les relacions d'afers o professionals, el rector de la parròquia, el notari que hagi pogut fer un contracte de lloguer o de matrimoni". Posteriorment, eren els consellers els que deliberaven la concessió o no de la ciutadania. Vegeu C. CARRÈre, ob. cit. (trad. al català), pp. 20-21; A. DE Fluvià I EsCORSA, Ciudadanos y burgueses honrados, el último grado de la nobleza en Cataluña, "Hidalguía", 253 (1995), pp. 769-783, esp. 770-771.
} 
segells, signà una àpoca davant del notari barceloní Francesc de Ladernosa conforme havia rebut 18 florins d'or per part de Bartomeu de Bonany, encarregat dels pagaments de l'Infant En Martí, pel preu de les tasques realitzades i del material utilitzat en un segell secret per a aquest ${ }^{16}$. Mig any més tard, el 16 d'abril de 1373, el Cerimoniós manava al Mestre Racional que admetés en el compte del protonotari reial Jacme Conesa la quantitat de moneda que aquest abonà per preu de 16 marcs d'argent, amb els quals Consolí havia de fer el segell de la majestat ${ }^{17}$. L'ordre es degué obeir sens retard, perquè en el compte que Jacme Conesa reté dels drets dels segells del Senyor Rei des del primer de gener fins l'últim d'abril del mateix any, apareix la constància de la retribució de 86 sous barcelonesos per marc a favor de Jacme Conesa qui havia comprat els 16 marcs a Galceran Herós, canviador de Barcelona, per tal que amb aquesta quantitat de metall Conquilí Blanch, mestre de fer segells, entallés el segell de les taules o de la majestat que el monarca feia fer de nou ${ }^{18}$.

En motiu del matrimoni de Matha d'Armanyac i l'Infant En Joan, duc de Girona, celebrat l'abril de 1373 a la catedral de Barcelona, també foren necessaris els serveis de Consolí Blanch en la confecció de tres segells, el major, el secret i el contrasegell, per a la nova esposa. El dia 11 de desembre de 1373, la Senyora Duquessa redactava des de València una ordre de pagament de 886 sous barcelonesos a l'argenter alemany per preu de les tasques realitzades i el 21 de juny següent es signava l'àpoca davant del notari Galceran Ortigues, secretari de Casa del Senyor Duc ${ }^{19}$.

\section{UNA CREU D'OR PER A L'ARQUEBISBE DE SARAGOSSA}

La data del 5 de juliol de 1378 marca una nova etapa de la trajectòria de Consolí, tot i que la notícia faci referència a una comanda pel

\footnotetext{
${ }^{16}$ Vegeu M. MITJȦ, ob. cit., pp. 188 i 204, doc. 1. L’aportació de M. Mitjà, procedent de l'Arxiu Històric de Protocols de Barcelona, significà poder recular un any en la cronologia de Consolí Blanch respecte de la fixada per F. de Sagarra.

${ }^{17} \mathrm{ACA}$, Cancelleria, reg. 1355, fol. 172 v. Vegeu apèndix, doc. I.

${ }^{18}$ Vegeu F. DE SAGARRA, ob. cit., pp. 83-84, nota 5.

${ }^{19} \mathrm{ACA}, \mathrm{RP}$, reg. 787, fol. XL r. i ACA, RP, reg. 613, fol. CIII v). Vegeu apèndix, docs. II i III, respectivament.
} 
Cerimoniós ${ }^{20}$. Com ja s'ha esmentat anteriorment, el sobirà ordenava la ràpida vinguda de Consolí des de Saragossa a Barcelona per tal de concloure els treballs iniciats l'any anterior en dos segells reials. Desconeixem si l'argenter acomplí el manament de desplaçar-se fins a Barcelona i d'acabar l'encàrrec, puix fins ara no s'ha trobat cap pagament emès a favor de l'estrasburguès per preu d'aquests segells concrets. Però, en tot cas, la dada resulta interessant perquè dirigeix la mirada de l'investigador cap a un nou centre de producció de Blanch, com fou la ciutat de Saragossa. Efectivament, a partir d'aquesta data, Consolí Blanch desapareix de la documentació barcelonina per emergir de les notícies saragossanes, ja que des de l'inici de 1379 i al llarg de tot aquest any es troba perfectament referit en motiu d'una creu d'or que realitzà per a Lope Fernández de Luna, arquebisbe de Saragossa ${ }^{21}$.

Aquests instruments arxivístics no només testimonien algunes de les quantitats de metall i altres materials que foren entregats a Consolí per tal de ser destinats a la creu, sinó també els jornals que rebé pels treballs esmerçats en l'obra i la constància que l'argenter treballava juntament amb col-laboradors. Tot i desconèixer l'organització del suposat obrador de Consolí, així com el nombre d'ajudants de què disposava, M. Serrano Sanz posà a la llum el contracte segons el qual el 12 de febrer de 1380 Consolí

\footnotetext{
${ }^{20}$ Vegeu la nota 14 del present article.

''És interessant la coincidència en el temps de Consolí Blanch i l'escultor i argenter Pere Moragues, en terres de Saragossa, ambdós al servei de Lope Fernández de Luna, arquebisbe de la Seu. Pere Moragues es traslladà a Saragossa pels volts de 1379 per a desenvolupar la tomba del mitrat, enllestida cap el 1382. En aquest mateix any, el Cerimoniós li encarregava la remodelació del sepulcre de la seva mare, Teresa d'Entença, que es trobava al convent de Sant Francesc de la mateixa ciutat, alhora que també li confiava la construcció de les tombes dels seus germans, Isabel i Sanç. A Saragossa, Moragues també hi desenvolupà la seva vessant d'argenter, realitzant la creu de Monforte (1381), adobant una pica d'argent pel rei i entallant un segell (1383) i, finalment, obrant la custòdia dels Corporals de Daroca, que acabà l'any 1385. La bibliografia sobre Pere Moragues és extensíssima i no pretenem ressenyar-la tota. Per això remetem a la citada per F. ESPAÑOL BERTRAN, Reliquiari dels sants corporals de Daroca. Pere Moragues, "Catalunya Medieval" (catàleg de l'exposició celebrada a Barcelona del 20 de maig al 10 d'agost de 1992), Barcelona, Lunwerg, 1992, pp. 242-245. Per a una aproximació a la figura de Lope Fernández de Luna, vegeu L. D’ARIEnzo, Lope Fernandez de Luna, arcivescovo di Saragozza, cancelliere di Pietro IV d'Aragona, "X Congreso de Historia de la Corona de Aragón", Institución Fernando el Católico, Saragossa, 1984, pp. 199-217; més sintètica és la referència que en fa $\mathrm{M}^{\mathrm{a}} \mathrm{C}$. LACARRA DUCAY, a Mecenazgo de los prelados zaragozanos durante la Baja Edad Media (1318-1520), "El espejo de nuestra historia. La diócesis de Zaragoza a través de los siglos" (catàleg de l'exposició celebrada a Saragossa, del 5 d'octubre de 1991 al 6 de gener de 1992), Saragossa, 1991, pp. 479-488. esp. 480-482.
} 
Blanch acceptava com a aprenent Joan Chaumont, natural de Bayona i fill d'un daurador'22.

A través dels diversos pagaments emesos hom pot endevinar el procés que seguí l'obratge de la creu. El 6 de febrer de 1379 Consolí rebia certa quantitat en retribució del seu salari i del dels seus companys, per les tasques realitzades al llarg dels mesos de febrer i març, a raó de 1 florí 8 diners per dia treballat, respectivament. Un nou pagament li fou satisfet dos mesos més tard, el $7 \mathrm{~d}$ 'abril, pel mateix motiu $\mathrm{i}$ amb un valor idèntic per jornada laboral que en el cas anterior ${ }^{23}$. Malgrat la remuneració del 6 de febrer no ho especifiqui, la proximitat temporal amb la primera informació on s'esmenta que la creu ja s'estava obrant -el 16 de març, com veurem a continuació-, indueix a creure que les sumes pagades d'ençà de primers de febrer obeïen als treballs efectuats en motiu de la creu ${ }^{24}$.

Es coneixen algunes de les quantitats de monedes d'or que a partir del 16 de març de 1379 es varen anar entregant en diferents remeses a Consolí Blanch, per tal de ser invertides en l'obratge de la creu, de manera que es poden considerar testimoni de l'etapa inicial de la seva realització. El 13 d'abril següent es precisa que els 6 marcs d'or que li foren entregats en forma de monedes anaven destinats al peu de la creu d'or que s'estava fent; sis dies més tard fou un cèrcol de pes de 2 marcs d'or el que se li donà amb el mateix objectiu i el 16 de juny rebé 30 "doblas cruzadas castellanas de cabeça", 29 florins d'Aragó i un marc d'or. Els treballs, doncs, devien anar per bon camí, en tant que el 3 i el 13 d'agost següents li era fet a mà mig marc d'or en cada ocasió, amb l'objectiu de modelar les imatges i figures

\footnotetext{
2"Vegeu J. F. ESTEBAN LORENTE, ob. cit., p. 333.

${ }^{23}$ Vegeu M. Serrano SANZ, ob. cit., p. 412. En aquest segon pagament és interessant la referència que es fa als dies que són descomptats del nombre total de jornades que comprèn el periode indicat, com són els nou diumenges i tota una sèrie de festes litúrgiques. en les quals es devia interrompre l'activitat laboral.

${ }^{-4} \mathrm{~A}$ l'església parroquial de Longares es conserva un calze que mostra els escuts esmaltats de $\mathrm{Mn}$. Aguilón i els de l'arquebisbe Lope Fernández de Luna. El fet que aquest primer pagament fos emès per Francisco Aguilón, rector de l'església de Longares, portà J.F. Esteban Lorente a proposar que el calze podria ser obra de Consolí Blanch. Tanmateix, creiem que en aquest document en concret té més pes el càrrec de Rebedor dels Emoluments dels Segells de l'Oficialat i del Vicariat de la Seu saragossana que també defensava Mn. Francisco Aguilón, que no pas el de rector, per la qual cosa interpretem que $\mathrm{Mn}$. Aguilón apareix com a responsable dels pagaments de la Seu $\mathrm{i}$, en conseqüència, dels treballs de la creu per a l'arquebisbe. En aquest sentit, recomanariem prudència a l'hora d'atribuir l'esmentat calze a Consolí Blanch, tenint en compte que no disposem de cap dada que expliciti clarament aquesta autoria, ni de cap obra documentada $i$ conservada de Consoli amb la qual poder comparar el calze. Vegeu J.F. ESTEBAN LORENTE, ob. cit., p. 332.
} 
dels esmalts que havien d'enriquir la decoració i la iconografia de la peça. Aquesta degué anar prenent forma definitiva durant el setembre següent, quan el dia 13 Consolí acceptava dos safirs i dos balaixos grossos i el dia 30 del mateix mes, tres safirs de color morat o "cardeno", un safir de color groc verdós o "cetrín" i quatre balaixos grossos que havien de ser col-locats a la creu, dins d'encastaments ${ }^{25}$.

Tot i ser escadusseres i en part marginals, les informacions que ofereixen els documents sobre les característiques de la creu certifiquen que la peça responia a la tipologia de la creu d'altar, en tant que estava dotada d'un peu per a ser disposada sobre l'ara. Tanmateix, l'ús de l'or com a material primer i les pedres precioses encastades fan pensar en la possibilitat que es tractés d'una Veracreu, atès que són els recursos propis de les creusreliquiari que contenien el lignum sacre ${ }^{26}$. La figuració dels esmalts, esmentada de manera lacònica en un dels documents, amb tota probabilitat devia representar la iconografia pròpia d'aquests objectes litúrgics, tal

\footnotetext{
413.

${ }^{25}$ Per a consultar totes aquestes referències, vegeu M. Serrano Sanz, ob. cit. pp. 412-

${ }^{26} \mathrm{La}$ predilecció vers les gemmes per embellir i enriquir el receptacle de la Veracreu no és una novetat. Ultra els exemplars conservats que mostren aquest recurs. són diversos els testimonis literaris que posen èmfasi en aquesta particularitat. Suger de Saint Denis ja es referí a les característiques del reliquiari que havia de contenir la reliquia de la Veracreu: "Habíamos hecho hincapié con toda la devoción de nuestro espíritu (...) en que la preciosa y vivificante cruz, el estandarte salutífero de la eterna victoria de Nuestro Salvador (...) debía ser adornada (...) y saludada con las palabras del apóstol San Andrés: «Salve Cruz, consagrada al cuerpo de Cristo y adornada con sus miembros como si fueran perlas" (...) por esta causa buscamos en todas partes, personalmente o por medio de agentes nuestros, gran cantidad de perlas preciosas y gemas, preparando para tan importante embellecimiento la más abundante recopilación de oro y gemas que pudimos encontrar y convocamos a los más experimentados artífices, procedentes de diversas partes; éstos realzarian, con labor diligente y paciente, la venerable cruz, en su reverso, gracias a la admirable belleza de aquellas gemas, y en su parte frontal, es decir, a la vista del sacerdote que oficia el sacrificio, mostrarian la imagen digna de admiración del Salvador. tal como se nos ofrece sufriente en la cruz. hasta hoy en día, en recuerdo de su Pasión". Vegeu J. YARZA et alt. Arte Mediev'al II. "Fuentes y documentos para la Historia del Arte". Barcelona, Ed. Gustavo Gili, 1982, p. 37. Més propera en el temps i en l'espai és l'eloqüent disposició que Jaume III de Mallorca fa de l'ordencment de la capella a les seves Lleis Palatines, en relació a aquesta tipologia: (...) "manam que en la nostra capella hi hagi cinc o sis creus, tant d'or com d'argent $i$ de cristall, adornades amb pedres precioses $i$ altres ornaments, a ti que així com la Creu de la nostra salvació fou decorada amb una pedra tan preciosa $\mathrm{i}$ incorruptible, com és el Fill d'Aquell qui, per salvar-nos, no perdonà el seu propi Fill, així també aquestes creus, obrades per representar aquella Veracreu, sien enriquides amb les gemmes més valuoses de la nostra natura incorruptible. (...) Una altra muntura de cristall, sostinguda per uns àngels daurats. estarà destinada a guardar dignament les relíquies més precioses, exceptuant l'Arbre de la nostra vida, el qual es pot encastar millor i més devotament en una de les creus d'or". Vegeu AAVV, Lleis Palutines. Palma de Mallorca. José J. de Olañeta Editor. 1991,p. 122.
} 
vegada les representacions dels evangelistes i els seus símbols o escenes $\mathrm{i}$ personatges al-lusius a la Passió i Mort de $\mathrm{Crist}^{27}$. Amb posterioritat a la mort de l'arquebisbe, la creu degué passar al tresor de la seu catedralícia, tal i com s'especifica en el testament del mitrat, escrit el 3 de febrer de $1382^{28}$.

\section{DE NOU, LA VINCULACIÓ AMB LA CORT ARAGONESA}

Els documents reials mantenen un silenci absolut durant l'etapa que Consolí Blanch treballà en la creu pediculada per a l'arquebisbe de la Seu saragossana, circumstància que ens podria indicar l'exclusivitat dels serveis de l'argenter respecte del mitrat. Quan s'aturen les notícies relatives a l'obratge d'aquesta peça litúrgica i, en conseqüència, les referides a Consolí, l'argenter apareix de bell nou relacionat en els registres de l'arxiu del Reial Patrimoni aragonès. En aquest període, l'estrasburguès es concentrà en els treballs per a la cort sobirana, en especial per al Cerimoniós i la seva quarta esposa, Sibil-la de Fortià, però també en alguns projectes en els quals sembla que el monarca hi mantingué alguna relació més indirecta.

El 8 de maig de 1380, des de Barcelona la Tresoreria Reial el remunerava amb 50 florins d'or en gratitud pels treballs efectuats en un segell secret per al Senyor Rei. Com que aquesta suma era atorgada per graciosa concessió del sobirà, amb tota seguretat els 50 florins excedien el preu estipulat pel material i per les "mans" del mestre, signe ben evident de la complaença del client i de la consecució d'un magnífic reeiximent en la comanda ${ }^{29}$. D'altra banda, a partir de finals de l'any 1380 i per espai d'uns tres o quatre anys, la cort del Cerimoniós itinerà per terres d'Aragó i de València $^{30}$. Aquest fet no trencà els lligams professionals que unien Consolí amb el monarca, sinó que més aviat els enfortí, tal i com es desprèn de la

\footnotetext{
${ }^{27}$ Per a l'estudi dels diferents objectes i complements sacres i litúrgics, vegeu B. MONTEVECCHI i S. VASCO ROCA, Suppellettile ecclesiastica. 4. Dizionari terminologici. Florència, Centro Di, 1988.

${ }^{28}$ Vegeu M ${ }^{\mathrm{a} C}$. LACARRa DucAy, ob. cit., pp. 481-482.

${ }^{29}$ Vegeu F. DE SAGARRA, ob. cit., pp. 83-84.

${ }^{30}$ Els documents expedits per la Cancelleria i per la Tresoreria així ho manifesten.
} 
també graciosa concessió de 10 florins d'or que el sobirà li donà, segons un albarà expedit a Saragossa el 13 de febrer de $1381^{31}$.

Un dels actes que tradicionalment es repetien cada Divendres Sant era l'ofrena amb què els monarques reverenciaven la Veracreu. Aquest ofertori consistia en el donatiu de monedes d'or o d'anells d'argent a la relíquia $^{32}$. Així, amb anterioritat a la Setmana Santa de 1381, degueren ser encarregats a Consolí Blanch els anells que la reina Sibil·la de Fortià havia d'oferir a la Veracreu, en tant que l'argenter cobrà 3 florins d'or d'Aragó per preu de la soldadura i del carbó que havia utilitzat en la manufactura d'aquells, segons un albarà expedit a Saragossa el 3 de juny d'aquell mateix any ${ }^{33}$. Un altre albarà escrit a la mateixa ciutat el 15 de novembre següent atesta la realització per part de Consolí Blanch d'una nova peça relacionada també amb la reina Sibil·la, per la qual cobrà 1042 sous 10 diners òbols jaquesos. En aquesta ocasió, es tractà d'un bust de la Mare de Déu amb un marcat caràcter votiu, en tant que la sobirana l'oferí a l'església de Santa Engràcia de Saragossa com a promesa per la malaltia que patia el Cerimoniós. Tot i que desconeixem l'aparença de la peça, el document exhumat per A. Rubió i Lluch facilita alguna informació de les diverses parts de què constava l'ex-vot. D'una banda, s'explicita que es tractava d'un cap dotat de cabells, corona, espatlles i pits, amb un esmalt en forma de cairó amb l'escut

\footnotetext{
"ACA, RP, reg. 374, fol. 7 v. Vegeu apèndix, doc. IV.

${ }^{32}$ Desconeixem, per ara, l'arrel d'aquesta tradició i el sentit que tenia. Tanmateix. en una miniatura procedent de les Molt Riques Hores del Duc de Berry, en concret la corresponent a l'Exaltació de la Santa Creu, hi veiem un paral-lelisme curiós pel que fa a les monedes. Al centre de la composició s'observa l'altar, ubicat dins d'una estructura arquitectònica hexagonal a manera de temple. Sobre l'ara s'hi disposa la creu-reliquiari de la Veracreu. en la seva tipologia de creu patriarcal amb doble travesser, ricament ornada amb pedres precioses. L'episodi, per a nosaltres, augmenta en interès per tal com ambdós extrems del braç transversal més llarg apareixen units per un cordó que penja lleugerament pel davant de la part central de la creu. Aquest cordó sosté una sèrie de monedes d'or, les quals també apareixen sobre l'altar disposades en rengle, mentre un dels sacerdots les compta. Curiosament, en primer terme $\mathrm{i}$ observant l'escena, l'il-luminador hi disposa la imatge de dos personatges coronats. potser l'Emperador Constantí i la seva mare l'emperadriu Helena. També caldria comprovar si hi pot haver alguna relació amb la tradició antiga pròpia dels ritus i costums funeraris com era l'òbol ofrena. Vegeu C. AmANTE SIMONI, Moneta e riti funerari nei secoli VI e VII. "La civitas Christiana urbanistica delle citta'italiane fra tarda antichita'e altomedioevo" (Torí, 1991), Torí, 1992, pp. 138-143; i M.D. DEL AMO GUINOVART, L'Ordo commendationis animae i la plàstica peninsular dels segles IV-VI d.C., "Spania, Estudis d'Antiguitat Tardana oferts en homenatge al professor Pere de Palol i Salellas", Barcelona, Publicacions de l'Abadia de Montserrat, 1996, pp. $37-46$.

${ }^{33}$ Vegeu A. LÓPEZ DE MENESES, Documentos culturales, ob. cit., p. 739, doc. 87.
} 
de la reina ${ }^{34}$. Malgrat es tracti de la primera obra d'aquestes característiques que realitzà Consolí Blanch de la qual en tenim constància, al llarg del regnat del Cerimoniós s'en coneixen diversos exemples que acomplien aquesta mateixa voluntat ${ }^{35}$.

\begin{abstract}
${ }^{34}$ Vegeu A. RUBió I LLUCH. ob. cit., p. 250, doc. 256. La succinta descripció que ofereix el document sembla correspondre's amb la tipologia pròpia dels busts-reliquiari que es van anar efectuant al llarg de la Baixa Edat Mitjana, els quals hostatjaven relíquies de la imatge representada a la part interior o bé exposades cap a l'exterior. mitjançant una concavitat a la part frontal, protegida per un cristall translúcid. Alguns exemplars han arribat fins als nostres dies, com el de santa Úrsula, obrat possiblement a Tortosa cap el 1350 i conservat a l'església parroquial de Sant Joan de Valls (Alt Camp), els de les santes Còrdula i Càndida de la Seu de Tortosa (ss. XIV i XV, respectivament), els de sant Valer o Valeri, sant Llorenç i sant Vicenç de la Seu de Saragossa, tots tres de cap el 1397, o els dels sants Abdó i Senén, realitzats en 1425 i 1440 pels argenters perpinyanesos Miquel i Francesc Alerigues, respectivament, per a l'església parroquial d'Arles del Tec. Ara per ara, la peça obrada per Consolí no sembla que disposés de cap relíquia o almenys el document no en dóna constància, signe eloqüent de la seva única intenció votiva. Per a visualitzar aquestes obres remetem a N. DE DALMASES-D. GIRALTMIRACLE. Argenters $i$ joiers de Catalunya. Barçelona, Edicions Destino, 1985, pp. 116-121: A. Martiniz Subias, Bust-reliquiari de Santa Úrsula, "Millenum. Història i Art de l'Església Catalana" (cultaleg de l'exposició celebrada a Barcelona. del 3 de maig al 25 de juny de 1989), Barcelona. 1989, pp. 318-319; F. Torralba Soriano, Sal Valero Obispo i J.F. Esteban LORENTE, Busto de San Vicente, "El espejo de nuestra historia...", pp. 120-121 i 344. respectivament.
\end{abstract}

${ }^{35}$ Un dels ex-vots més ben documentats pertanyent al regnat de Pere III és una galera d'argent, amb vuit esmalts que representaven l'escut $i$ el timbre reials i dotada d'un centenar de rems d'argent, que el Senyor Rei oferí al monestir de Santa Maria de Montserrat (ACA, RP. reg. 322. fol. CVI r.). L'obra. efectuada per Pere Bernés. valorada en 1274 sous 2 diners obols barcelonesos i pagada en diferents terminis a partir de l'abril de 1344. es troba perfectament referida a la Crònica del Cerimoniós quan després de la Pasqua de 1344, el monarca decidí. "ans que dret camí féssem l'entrada de Rosselló. anàssem fer reverència a nostra Dona de Montserrat". La informació, però, va més enllà de l'anotació de la voluntat i del propòsit del sobirà per visitar el Monestir, ja que el text narra amb tot detall que "dijous matí, a vint-e-nou d'abril partint d'aquí [Collbató] cavalcant, anam entrò al peu de la costa de Montserrat, e aquí descavalcam (...). En vista del monestir de Montserrat, isqué 'ns a carrera lo prior de Montserrat e reebé'ns reverentment, (...). e, aprés menjar, ab lo prior ensems, anam presentar a la dita Verge una galea ab totes ses eixàrcies d'argent en reverència de la victòria que ens donà lo dia que prenguem terra a Mallorques, la qual hi havíem feta portar ans de dos dies que nós hi fóssem. E. presentada la dita galea, fem-nos venir los ermites de Montserrat, los quals dels seus ermitatges havia fets al monestir devallar lo dit prior, als quals diguem e pregam que per ells fos constituïda especial oració, la qual diguessen a certes hores de dia e de nit per nós e per les nostres companyes". Vegeu F. SoldEVILA, Les quatre grans cròniques, Barcelona, Ed. Selecta, Col-lecció Biblioteca Perenne, 1971, pp. 1066-1067. Si el motiu de l'ofrena d'aquesta galera pot considerar-se de caràcter públic i politic. d'entre els ex-vots argèntics presentats pel monarci en trobem d’altres amb una significació més personal o privada. Aquest seria el cas. per exemple. d'una imatge d'argent que representava la figura de la reina Maria de Navarra. primera esposa del Cerimoniós, que aquest oferí a l'església de Sant Jaume de Compostel-la. Executada també per Pere Bernés. l'argenter degué cobrar 1000 sous barcelonesos segons un albarà expedit a València el 6 de març de 1346 (ACA. RP. reg. 868, fol. LXVI r.). La raó i la necessitat d'oferir un ex-vot amb la figura de l'esposa suggereix qüestions relacionades amb la salut o la maternitat, especialment si es té en compte que Maria de Navarra fins l'any 1346 havia donat tres filles al seu espòs: Constança (1340), Johana (1344) i una tercera nena, nascuda 
Si hi ha alguna qüestió que expressi de manera clara la satisfacció del monarca envers els serveis de Consolí Blanch és el tracte d'argenter de Casa del Senyor Rei, amb el qual apareix rubricat en el document relatiu al bust suara esmentat $i$ en alguns dels que el segueixen ${ }^{36}$. Aquesta distinció no la reberen massa personatges vinculats a la cort, sinó només aquells que van merèixer la confiança del sobirà $i$ que excel-liren en els seus coneixements. La conseqüència documental d'ésser distingit amb aquest títol és l'aparició de pagaments trimestrals per l'assistència prestada a la cort, en funció dels dies treballats. Efectivament, si el 15 de novembre de 1381 Consolí Blanch era considerat argenter de Casa del Senyor Rei es devia a què l'argenter hi havia estat treballant un cert temps de manera intensiva i exclusiva durant el període comprès entre l'agost anterior i la darreria d'octubre, tal i com ho prova el pagament per valor de 90 sous corresponents al salari.o quitació ordinària del trimestre indicat del mateix any ${ }^{37}$. Atesa la pèrdua parcial de llibres de la Tresoreria concernents a les dates on apareixen aquestes retribucions, és impossible asseverar amb seguretat fins quan l'estrasburguès es dedicà per complet al servei de la Corona, en tant que la següent remuneració exhumada en motiu del seu salari correspon al trimestre iniciat el dia 1 de novembre de $1383^{38}$.

l'estiu de 1345, que morí al cap de pocs dies. A partir d’aquest moment el monarca es preocupà per la qüestió successòria, així com ell mateix expressa que "stants en València, perpensam e albiram que. per volentat de Déu. no engendràvem sinó filles: anàns lo cor si es pogra fer de dret que nostra filla Constança, primogènita. en cas que moríssem sens infants mascles. succeis aprés nós en los regnes e terres nostres". circumstància que motivà la reunió de diversos savis en dret civil i canònic que aconsellaren al sobirà. Vegeu F. SoldEvILA. ob). (it.. p. 1091. A la Crònica, el Cerimoniós assevera que aquell mateix hivern de 1345 la reina tornava a trobar-se en estat, desiliurant un fill nascut a principis d'abril de 1346. que sobrevisqué un dia $i$ causà la mort de la mare. Aquesta data que proporciona el text es correspon perfectament amb la cronologia de la imatge d'argent. fet que podria indicar el missatge que aquella portava implicit, és a dir, la petició dirigida a Sant Jaume per tal que la criatura que Maria de Navarra estava gestant fos un mascle. La mateixa preocupació dinàstica es féu palesa quan - tal i com posa de manifest J. YARZA LuACES a María de Navarra y la ilustración del Libro de Horas de la Biblioteca Nazionale Marciana. dins: "Libro de Horas de la reina María de Navarra". Barcelona, Moleiro (ed.), 1996, p. 248- la reina es féu retratar en el seu llibre d’hores davant la Mare de Déu de la Llet.

${ }^{36}$ Recentment, he dedicat un article que es cenyeix a l'estudi dels argenters que foren nomenats amb aquest títol $i$ a tot allò que implicava ostentar-lo. Vegeu A. MOLINA I CASTELLÀ, L'"argenter de Casa del Senyor Rei", ob. cit. En premsa.

${ }^{37} \mathrm{ACA}, \mathrm{RP}$, reg. 375, fol. CXLIX r. Donat l'esquematisme que presenten els documents relatius als pagaments de quitacions ordinàries, en aquests casos optem per no oferir la transcripció del document a l’apèndix d'aquest article, ja que la informació que ofereixen és la que s'utilitza en la redacció del present text.

${ }^{38} \mathrm{ACA}, \mathrm{RP}$, reg. 378, fol. CXXXII v. 


\section{PARAUles DE RECONEIXEMENT VERS UN ARTÍFEX}

El període que resta entre les dues quitacions ordinàries acabades de citar no constitueix una llacuna documental respecte de la trajectòria de Consolí, ja que es constaten d'altres notícies, algunes d'elles relacionades també amb la cort aragonesa, però que no fan referència a l'entrega exclusiva de l'artífex a les comandes palatines. Tanmateix, en totes elles es palesa el contacte entre el monarca i l'argenter, així com l'admiració, la preferència i la protecció que el sobirà li dispensava.

En aquest sentit, un dels únics elogis del Cerimoniós a Consolí que ha arribat fins als nostres dies apareix en una disposició del sobirà, datada a València el 2 d'abril de 1382, segons la qual ordenava que fos Consolí Blanch qui executés la custòdia d'argent que s'havia de fer per a la Seu de Tortosa, ja que en opinió explícita del monarca el "feel argenter de Casa Nostra... es un dels suptils maestres de la sua art qui sien en nostra senyoria. segons que ns ha mostrat esperiencia de sa obra la qual ha feta a Nós" ${ }^{39}$. A fe que l'admiració reial per la destresa de l'estrasburguès és més que definitiva. En quant a la custòdia, tot sembla indicar que l'obratge no arribà a bon port i que el manament del Cerimoniós no s'acomplí, atesa l'absència de notaments on constin les despeses ocasionades en motiu de la factura de la peça. Tot i que el monarca expressés clarament que la custòdia es feia per ordinacion nostra, no es preveia que fos ell qui contactés o pactés directament amb l'orfebre, sinó que la lletra del monarca localitzada a la Cancelleria Reial anava dirigida a un personatge o institució -el bisbe o el capítol de la Seu?-, el nom dels quals no queda reflectit en el registre.

Arribats a aquest aparent atzucac, són els documents tortosins i valencians els que donen llum a l'afer. En relació a l'existència d'una custòdia d'argent obrada l'últim terç del segle XIV per a la Seu de Tortosa, J.L. Villanueva explica que en el segle XVII es va encarregar una nova

\footnotetext{
${ }^{39}$ Aquesta notícia la facilità $\mathrm{F}$. de Sagarra, qui la localitzava a la secció de Cancelleria, reg. 1274, fol. 26 r (vegeu F. DE SAGARRA. ob. cit. p. 84. doc. LXX). Tanmateix, cal precisar que aquesta mateixa nova apareix escrita dues vegades, la primera en llengua catalana en el recte i la segona en llatí en el vers del mateix foli. D’altra banda, és possible que $\mathrm{N}$. de Dalmases es refereixi a aquest document quan registra l'obratge d'una custodia d'argent per a la catedral de Barcelona [sic] per part de Consoli Blanch, segons una carta expedida a València el 2 d'abri de 1381 (vegeu N. DE DALMASES, Orfebreria catalana medieval, ob. cit., vol. II. p. 36 i N. DE DALMASES, Els argenters de la cort, ob. cit., p. 206).
} 
custòdia a l'argenter valencià Eloi Camanyes i al seu gendre Agustí Roda, argenter de Tortosa. Per a obrar-la fou necessari desfer l'antiga, realitzada l'any 1382 pels argenters valencians Pere Capellades i Pere de París ${ }^{40}$. En aquest mateix any els foren entregats 100 marcs d'argent i varen prometre finalitzar-la per espai de dos anys, tot i que l'enllestiren el 1393, data de l'àpoca de 1179 lliures 6 sous per preu de l'argent que s'hi invertí. Sempre segons J.L. Villanueva, a la catedral de Tortosa hi ha constància de diferents donacions del rei, del bisbe i del capítol catedralici per aquest fi. Entre elles, l'autor cita que el 10 de gener de 1388 els artífexs reberen "lapides desencastatos sequentes, qui encastari debent in hostiaria reliquiarii quod nos facimus, fabricamus et operamur... et sunt ut sequitur numero septem: primo, unum topasium; item, unum maracde; item, quatuor çafirs inter magnos et parvos; item, unum calçadoyne entallat..."4l. Encara més, E. Bayerri en citar les efemèrides tortosines, esmenta que el dia 7 de juny de 1393 l'argenter valencià Pere París entregà al capítol la primera custòdia de corpus de què disposà la catedral, certificant que el preu de l'objecte preciós fou de 1179 lliures. L'autor comenta que fou costejada per Joan I el Caçador, pel bisbe Hug de Llupià, pel Capítol i per alguns personatges de la ciutat ${ }^{42}$. Així doncs, desconeixem de moment els esdeveniments ocorreguts a l'entorn de la factura de la custòdia en relació amb Consolí Blanch, ja que els testimonis escrits evidencien que l'estrasburguès no hi participà. L'especial interès per part del Cerimoniós a l'hora de concedir l'afaiçonament de la peça a Blanch degué veure's interceptat per la impossibilitat de Consolí d'assumir l'encàrrec o qui sap si per l'oposició del propi capítol catedralici. Amb tot, la coincidència cronològica entre el manament del monarca i l'encàrrec a Peris i Capellades manifesta que en ambdós casos es fa referència a una mateixa obra.

Sense perdre la força i el sentit de les paraules d'admiració del Senyor Rei i en estreta significació amb aquestes, el 23 de maig de 1382 i

\footnotetext{
${ }^{40}$ Es tracta sens dubte de Pere Peris, argenter de València, segons es desprèn del document exhumat per J. Sanchís Sivera en el qual el 6 de maig de 1393 els jurats de València recomanen als bisbe i capitol de la Seu de Tortosa que paguin a Pere Peris el preu degut per la custòdia que havia obrat per a aquella catedral. Vegeu J. SANCHís SIVERA. La orfebreria valenciana en la Edad Media, a "Revista de Archivos, Bibliotecas y Museos". XLIII. 1922, pp.13-14.

"Vegeu J.L. VILlanUeVA, Viage literario a las iglesias de España, Madrid, Imprenta Real, 1806, vol. V, pp. 144-145.

${ }^{42}$ E. BAYERRI BERTOMEU, Historia de Tortosa y' su comarca, Tortosa, Impremta d'Algueró i Baiges, 1959, vol. VIII, p. 601.
} 
estant a València, el sobirà honrà l'argenter i domèstic reial Consolí Blanch amb el càrrec de mestre del gravat $\mathrm{i}$ assajador de totes les monedes d'or $\mathrm{i}$ d'argent que es batessin a la ciutat de Saragossa i a tot el regne d'Aragó, amb els mateixos privilegis, prerrogatives, llibertats, franqueses i immunitats de què gaudiren aquells qui el precediren en el càrrec ${ }^{43}$. Així doncs, deu anys després del primer contacte amb la casa reial aragonesa -sempre segons els documents-, Consolí Blanch arribà al cim més alt de la seva trajectòria professional. Si designar-lo argenter de Casa del Senyor Rei no devia ser prou recompensa per a un monarca que considerava que el seu fidel argenter era un dels mestres més subtils del seu art que havia conegut, hem de creure que el Cerimoniós aprofità la primera avinentesa per honorarlo amb un dels ministeris més exclusius de l'àmbit de l'orfebreria reial.

Tan sols dues notícies s'allunyen de la trajectòria professional de Consolí, per endinsar-se en l'àmbit més personal i privat. El 30 de juliol de 1382 Pere III escrivia des d'Algesires a Domingo Pons, canonge d'Osca i fundador del Col·legi de Santa Maria, un dels col-legis per a estudiants més reconeguts de l'Estudi General de Lleida ${ }^{44}$. En aquesta carta li recriminava no haver rebut resposta de la petició que li havia fet d'acollir a casa seva al fill d'en Cossoli de Casa Nostra, en tant que volia anar-hi a estudiar ${ }^{45} \mathrm{i}$ demanava a Pons que li donés contesta perquè Consolí pogués saber si hi podia comptar $\mathrm{o} \mathrm{no}^{46}$. Cal suposar que Domingo Pons acceptà el fill de

\footnotetext{
${ }^{43}$ La cota arxivística d'aquesta noticia fou facilitada per A. Rubio $\mathrm{i}$ Lluch, el qual en referència al document exhumat. que no transcrivia. afirmava que Consolí Blanch feia els encunys de les monedes de Saragossa. El contingut del regest. insuficient. fou corregit per A. López de Meneses, qui a més transcriví el document. Vegeu A. RUBió I LLUCH, ob. cit. p. 250, doc. 256, nota 1; i A. LÓPEZ DE MENESES, Documentos culturales, ob. cit. pp. 744-745, doc. 94. El mateix honor havia estat atorgat l'any 1369 a l'argenter valencià Pere Bernés, el qual fou designat escultor dels encunys de la seca d'or de la ciutat de València i de qualsevol altre lloc del regne. Vegeu J. SANChís SIVERA, La esmaltería valenciana en la Edad Media, a "Archivo de Arte Valenciano". VII, 1921, p. 41, doc. 8.

${ }^{H}$ Domingo Pons fou nomenat en diverses ocasions procurador per part dels bisbes de Lleida, Barcelona, Urgell i Tarragona. Vegeu R. GAYA MASSOT. Apostillas monográficas al Colegio de Domingo Pons, a "Ilerda". IV (1945), pp. 7-17: J. RIUS I SERRA, Aportación doccumental al Colegio de Domingo Pons. "Miscelánea de trabajos sobre el Estudio General de Lérida". Consejo Superior de Investigaciones Científicas, 1949. vol. I, pp. 59-63.

${ }^{45}$ ACA, Cancelleria, reg. 1274, fol. $133 \mathrm{r}$. Vegeu apèndix, doc. V.

"Fins ara, no s'han localitzat ni la primera carta que el sobirà adreçà a Domingo Pons. sol-licitant-li l'acolliment del fill de Consolí, ni la resposta que aquell li envià. Malgrat això. la petició pel descendent de Blanch no és única, ja cque el monarca es preocupà per l'allotjament d’altres fills de servidors seus. com ara els del mestre Simó de Prades, físic de Casa del Senyor Rei, que foren acceptats per Domingo Pons i dels quals es conserva la carta d agraiment que li dispensà el Cerimoniós. Vegeu A. LÓPEZ DE MENESES, Florilegio documental, ob. cit. . XVIII
} 
Consolí, en tant que el 18 de desembre següent, el Cerimoniós es dirigia als bisbe i Capítol de la Seu de Lleida per recomanar-los Nicolau Blanch, estudiant a la ciutat de Lleida, amb l'objectiu d'ocupar el primer benifet que romangués vacant en l'esmentada Seu, de manera que gràcies a aquest li fos possible continuar estudiant ${ }^{47}$.

Novament, no tenim constància que Nicolau Blanch aconseguís algun benifet a la Seu lleidatana, però en tot cas és curiós assenyalar que el 9 d'octubre de 1383 el Cerimoniós dirigia una lletra des de Montsó a Consolí Blanch, ordenant-li la seva presència a la cort. Aquesta carta no dóna indicis del lloc on es trobava l'argenter, tot i que una altra missiva escrita el mateix dia pel sobirà deixa clar que Blanch era a Lleida, per tal com el Cerimoniós pregava al Capítol de la Seu que permetés anar a Consolí a la seva cort, con

\section{(1952), p. 171, doc. LXXXIX.}

${ }^{47}$ Vegeu A. LÓPEZ DE MENESES, Florilegio documental, ob. cit., XVIII (1952), pp. 171172, doc. XC. Amb posterioritat a la localització d'aquesta notícia publicada per A. López de Meneses, vam adonar-nos que A. Rubió i Lluch ja havia registrat aquesta nova informació, tot i que no la referenciava dins del corpus documental, sinó en una llista d'estudiants a l'Estudi de Lleida que presentà dins l'apèndix anterior a la col-lecció de documents del segon volum. Vegeu A. Rubió i Lluch, Documents per l'Història, ob. cit., vol. II, p. CXI. Tot i que les notícies són molt minses no podem passar per alt la presència a partir del novembre de 1392 d'un tal Nicolau Blanch, batxiller en lleis, en els fets de la successió de Foix en relació a la Corona de Navarra. En aquesta contesa apareix com a advocat de la cort de Carles III, actuant en defensa del monarca i de la seva tia Agnès de Navarra, repudiada pel seu marit Gastó, comte de Foix. Atestat més endavant com a conseller de Carles III, estigué al servei d'aquest monarca fins a la seva mort ocorreguda entre el 26 de juliol, data en què consta encara viu, $i$ el 18 d'octubre de 1418, ja difunt. Vegeu. J.R. CASTRO. Catálogo del Archivo, ob. cit. XXXII (1963), docs. 866 i 927, respectivament. Desconeixem si aquest Nicholau Blanch podria ser el mateix Nicholau Blanch documentat com a fill de Consolí i estudiant de l'Estudi General de Lleida des de finals de 1382. Les sospites es fan més fortes a partir de la vinculació que s'establí entre la cort navarresa i l'argenter Consolí Blanch des de l'any 1385, com més endavant veurem. Vegeu l'extensíssima documentació que posa de manifest les tasques que Nicolau Blanch desenvolupà a la cort navarresa a J.R. CASTRO, Catálogo del Archivo, ob. cit., XIX (1957)-XXXV (1964). Algunes referències també poden trobar-se a J.R. CASTRO, Carlos III el Noble, rey de Navarra, Pamplona, Institución Príncipe de Viana-Diputación foral de Navarra, 1967, pp. 288 i 424. D'altra banda i en relació amb aquest àmbit més privat de l'estrasburguès, tampoc obviarem una notícia amb la qual hem topat quan intentàvem aclarir els fets de la custòdia de Tortosa. J. Matamoros dedica part de la seva publicació als mestres que treballaren a la Seu tortosina i és sota l'epígraf dedicat als argenters on cita un A. Nicolau Blanch, argenter, que l'any 1446 apareix en un dels llibres de la Sotstresoreria en cobrar 7 lliures "per adobar la creu de la relíquia de la Cinta de Santa Maria, que era trencada". Vegeu J. Matamoros, La catedral de Tortosa. Trabajos monográficos acerca de su construcción y de su contenido artístico y religioso, Tortosa, Editorial Catòlica, 1932, p. 85. Si bé cal ser prudent, hom no pot evitar d'establir la relació patronímica, la coincidència professional entre Consolí $\mathrm{i}$ aquest altre mestre $\mathrm{i}$, finalment, la possibilitat de situar cronològicament Nicolau Blanch i A. Nicolau Blanch en dues generacions successives. 
sens vostra licencia fer non pugués bonament segons havem entès ${ }^{48}$. És evident el poder que el Capítol exercia sobre l'estrasburguès segons les paraules del mateix sobirà, de manera que hom ha de creure que Consolí estava treballant per al capítol catedralici, tot i que desconeixem el projecte per al qual havia estat sol-licitat a la ciutat del Segre. L'argenter obeí l'ordre del monarca, ja que des del primer de novembre de 1383 i fins al juliol de l'any següent treballà contínuament a la cort, cobrant els 180 sous barcelonesos corresponents a cadascun dels tres trimestres complets, encara que no hi ha constància de les tasques que hi efectuà ${ }^{49}$. Tan sols una notícia s'infiltra en aquest període al servei del Cerimoniós i té relació amb l'obra que havia deixat enrere a la Seu de Lleida. Des del monestir de Santa Maria de Poblet, el 23 de juliol de 1384 el sobirà es dirigia a Pere Miró, lloctinent de la curia i vicari de Lleida, fent-li saber que l'argenter havia comparegut davant d'ell queixant-se de l'incompliment del tracte que públicament havia efectuat Pere Miró feia un mes, prometent-li que lo dia de la dita promissió seria remunerat per les obres d'argent que havia fet. El monarca recriminava a Miró no haver satisfet Consolí, malgrat les diverses vegades que l'argenter li havia reclamat el pagament, tot i que bé que sabessets ell haver gran necessitat de diners. Finalment, el Cerimoniós li ordenà remunerar l'estrasburguès sota pena de 500 morabatins i li feia saber que no fes perdre massa temps a Consolí per aquest afer a Lleida, en tant que el monarca el necessitava molt a la cort ${ }^{50}$.

Són diverses les qüestions que sorgeixen de la lectura atenta d'aquest document i que obren nous interrogants sobre la figura de Consolí. En

\footnotetext{
${ }^{48} \mathrm{~J} . \mathrm{M}^{\mathrm{a}}$ Madurell i Marimón donà a conèixer la primera d'ambdues cartes, però incomprensiblement no detectà la segona, que es troba en el vers del mateix foli. Ens sembla prou interessant l'existència d'aquesta altra missiva, en tant que ofereix noves pistes per investigar, alhora que completa les dades obtingudes (ACA, Cancelleria, reg. 1281, fol. $131 \mathrm{v}$. Vegeu apèndix, doc. VI). Per a la primera lletra, vegeu J.Ma MADURELL I MARIMÓN, ob. cit., p. 321 , doc. 32 .

${ }^{49}$ Vegeu els tres pagaments per quitacions ordinàries a ACA, RP, reg. 378. fol. CXXXII $v$; reg. 379, fol. LXXXVIII v. i fol. CXXIIII $r$, respectivament.

${ }^{50} \mathrm{~A}$. Rubió i Lluch donava la referència d'aquest document, indicant que es tractava d'una notícia relativa a l'obratge de la custòdia de la seu de Tortosa, tot i que no oferia la transcripció. La consulta del document posà de manifest que no es tractava d'aquesta peça, sinó de les tasques imprecises que efectuà per a la catedral de Lleida. Vegeu A. RUBIÓ I LLUCH, Documents per l'História, ob. cit., p. 250, doc. 256, nota 1. El document aparegué transcrit a A.L. Mayer, El estilo gótico en España. Madrid-Barcelona, Espasa Calpe S.A.. 1929, p. 272, nota 1. Agraeixo a la Dra. Francesca Español haver-me posat en coneixement l'existència d'algunes referències sobre Consoli Blanch en aquesta obra i a la Dra. Rosa Terés $i$ al Dr. Joan Domenge els seus comentaris i directrius durant el procés de la investigació.
} 
primer lloc, cal destacar que efectivament durant el període en què l'argenter fou retribuït cada trimestre per la Tresoreria realitzà diferents tasques per a la cort, en tant que el monarca reconeix necessitar-lo sens dilació. En segon lloc, la seguretat que Consolí efectuà treballs d'argenteria per a la Seu de Lleida; si en un inici ho proposàvem com a hipòtesi, a partir d'aquesta carta del Cerimoniós, queda palès que Consolí hi dugué a terme algun obratge. Per últim, la situació econòmica del mestre. Realment es fa difícil d'endevinar el punt de vista exacte des del qual s'ha de valorar la informació, alhora que són moltes les preguntes que hom es pot plantejar. En principi, sembla que un argenter que es trobava treballant amb certa continuitat per a la Corona, amb algunes incursions fora d'ella, i que en certs períodes cobrava un salari determinat pel fet de dedicar-se exclusivament al servei de la cort, no hauria de patir la manca de diner líquid. Ara bé, també podria entendre's que alguns encàrrecs d'obra d'argenteria en ocasions comportaven una forta inversió inicial en metall noble que l'argenter no recuperava fins que no entregava la peça, sense oblidar la infinitat de casos de demora en els pagaments de la Casa Reial, especialment al llarg del regnat del Cerimoniós.

\section{UNA NOVA CLIENTELA: LA CORONA NAVARRESA}

Els dubtes respecte de la situació econòmica de Consolí Blanch són difícils d'escatir, però no es poden deixar de tenir en compte sobretot si tenim present que pocs mesos més tard apareix a la documentació de la Corona de Navarra. A partir de l'any 1385 i fins a l'abril de 1397 Blanch treballà de manera esporàdica per a Carles II el Dolent i el seu fill Carles III el Noble, per als quals realitzà essencialment matrius de segells. Tot i així, l'àmplia etapa que marquen les dues dates és poc menys que enganyosa, per tal com en realitat es constata un buit documental al qual ens hem referit en els primers apartats del present treball. Del 1385 en coneixem una única notícia, de manera que juntament amb les tres informacions pertanyents al primer semestre de $1386 \mathrm{i}$ amb les dues que es localitzen l'any 1397, no conformen un corpus documental massa dens com per assegurar una vinculació prou sòlida amb la cort de Navarra, sinó que més aviat hem de parlar d'uns contactes puntuals.

La dada que enceta aquesta nova etapa correspon a l'any 1385; fa referència a l'obratge de dos segells de la majestat per a Carles II i un tercer 
per a Charles de Beaumont, alferes de Navarra ${ }^{51}$. Més tard, el 4 de març de 1386 Concelín Blanch, argenter de la ciutat d'Estrasburg a Alemanya, cobrava 50 lliures de carlins "prietos" per algunes obres de segell pel mateix sobirà. El mes següent, el 13 d'abril, era un anell per a l'Infant Carles, futur Carles III, l'objecte que Consolí obrà per valor de 8 francs 4 florins. Potser en relació amb aquesta obra, el 21 d'abril, tan sols uns dies més tard, l'estrasburguès rebia 30 lliures per esmena d'algun servei, que no s'especifi$\mathrm{ca}^{52}$.

Després del silenci documental esmentat, el 7 d'abril de 1397 recuperem les traces de Consolí als instruments navarresos. En aquesta ocasió l'argenter havia realitzat un encenser que pesava 6 marcs 2 unces 7 esterlines, per preu de 85 florins 3 quarts 3 sous. Atès que en diverses ocasions li havien estat entregades diferents quantitats de moneda $-o$ fins $\mathrm{i}$ tot algunes peces treballades del rei i de la comtessa de Foix per a ser foses i reutilitzar-ne el material-, del preu total li fou deduït el metall lliurat, de manera que finalment Consolí rebé 85 lliures 4 sous 2 diners. En la següent notícia registrada, una àpoca signada el $20 \mathrm{~d}$ 'abril del mateix any, Consolí reconeix haver estat remunerat amb 64 florins 1 quart 20 diners per a la realització d'un encenser, alhora que certifica que li foren entregades monedes per valor de 6 marcs 2 unces 7 esterlines d'argent blanc, en dues remeses $^{53}$.

Resseguint les notícies exhumades per F. Mendoza i J.R. Castro, hom s'adona que la secció de "comptos" de la documentació navarresa on es registren aquests instruments no presenta buits documentals notoris.

\footnotetext{
${ }^{51}$ No tenim constància de la quantitat que rebé Consolí en retribució d'aquests treballs. Vegeu F. MEndozA, ob. cit., pp. 41-42 (non vidit). Charles de Beaumont era fill natural de l'Infant En Lluís, germà de Carles II de Navarra, i de Maria de Lizarazu. L'any 1379 Carles II el nomenà alferes del regne per tal com gaudia de la confiança del monarca i del seu successor. Vegeu una aproximació a aquest personatge a J.R. CASTRO, Carlos III el Noble, ob. cit., pp. 463-468.

52Vegeu J.R. CASTro, Catálogo del Archivo, ob. cit., XVI (1956), p. 56, doc. 127; p. 77 , doc. 180 i p. 81 , doc. 190 , respectivament.

${ }^{53}$ Vegeu J.R. CASTro, Catálogo del Archivo, ob. cit., XXII (1958), pp. 185-186, doc. 412 i p. 197, doc. 439, respectivament. Es possible que ambdues notícies es refereixin a una mateixa peça, per tal com el pes de l'encenser del primer document era de 6 marcs 2 unces 7 esterlines $\mathrm{i}$ les monedes entregades que apareixen en el segon document pesaven 6 marcs 2 unces 7 esterlines. Tanmateix es fa difícil entendre el motiu pel qual en el document del 7 d'abril no apareixen registrades les dues remeses de monedes lliurades a l'argenter que certifica l’àpoca signada per Consolí, alhora que és notori que en aquesta àpoca no es fa esment del primer pagament efectuat el 7 d'abril.
} 
Suposant que Consolí s'hagués desplaçat de Saragossa a la cort navarresa per dedicar-se al servei de Carles II o del seu fill, el futur Carles III, hi hauria constància de la seva dependència laboral o bé es denotaria una producció per aquest àmbit més sovintejada i seguida en el temps. En conseqüència, és obvi pensar que Consolí no es degué moure de Saragossa, sinó que fou la cort navarresa o algun dels seus membres els que es desplaçaren a la capital aragonesa per fer-li uns encàrrecs concrets. A la recerca de notícies que certifiquin aquesta hipòtesi, una explicació la podríem trobar en una estada de l'Infant Carles a Saragossa l'abril de 1386, com a mínim des del dia 13, tot i que degué ésser curta perquè el dia 19, festivitat de Dijous Sant, es trobava a Tudela de retorn de Saragossa ${ }^{54}$. Les coincidències, però, no acaben aquí, ja que el motiu del viatge de l'Infant a la ciutat de l'Ebre fou la negociació amb l'Infant En Joan. Duc de Girona, del matrimoni entre l'Infant En Jaume, primogènit del Duc, i Dona Joana, filla del navarrès ${ }^{55}$.

Deixant el buit informatiu certament important que comporta el període 1386-1397 i recercant els motius dels nous contactes del ja Carles III amb Consolí Blanch, cal fer referència a una de les qüestions que políticament preocupà més al monarca: la pèrdua de les terres que Carles V de França guanyà a Carles II. Amb la intenció de negociar aquest assumpte, l'any 1392 Carles III organitzà un viatge a França que no s'arribà a fer, possiblement per les informacions negatives que li proporcionà una ambaixada que s'havia avançat. Tanmateix, l'agost de 1396 el monarca ordenà de nou l'organització d'aquesta sortida, per la qual cosa en els mesos següents es feren diferents recaptes per finançar l'empresa. Enllestint els preparatius, Carles III romangué a la població navarresa de Monreal els darrers dies de març, tot l'abril i els primers de maig, des d'on ordenà als

\footnotetext{
${ }^{54}$ Vegeu l'itinerari en qüestió a J.R. CASTRO, Carlos III el Noble, ob. cit. p. 115.

${ }^{55}$ Vegeu J. Zurita. Anales de la Corona de Aragón. Saragossa, 1668, vol. II, fol. 389 (non vidit). Tot $\mathrm{i}$ aixi, amb anterioritat a aquest fet, la documentació navarresa posa de manifest e contacte sovintejat entre l'Infant Carles de Navarra i alguns servents del Cerimoniós i del fill d'aquest, el Duc de Girona. En aquesta línia al llarg del 1385 apareixen diversos pagaments que en donen testimoni, com per exemple: Carles II concedeix una pensió anual de 400 lliures de carlins "prietos" a Pero Jordà d'Urriés, escuder del Cerimoniós (12 de gener de 1385): 30 florins al "naynne" del Duc de Girona (8 d'abril de 1385); 20 colzes de drap i 100 florins a Simó Sescomes, camarlenc del Duc de Girona (16 de maig de 1385) i 20 florins a Johan de Bar, herald del mateix duc (18 de setembre de 1385). Vegeu J.R. CASTRO, Catálogo del Archivo. XV (1956). p. 299. doc. 702; p. 360. doc. 844; pp. 387-388, doc. 908 i pp. 482-483. doc. 1121. El grau d'amistat i la bona entesa que en un inici sembla que hi hagué entre l'Infant Carles i el Duc de Girona, podria haver estat motiu de comentaris per part de Joan d'Aragó sobre la fama i la versatilitat de l’argenter estrasburguès.
} 
oïdors de comptes de la seva cort els pagaments a mercaders i servents de la Corona per diversos objectes, productes i materials necessaris que feren comprar o que procedien de Saragossa ${ }^{56}$, així com a diferents argenters per preu de les obres que havien realitzat ${ }^{57}$. Totes aquestes despeses obeïen a la voluntat del monarca de demostrar el luxe $i$ el prestigi de la seva cort davant l'homòleg francès. El fet que molts dels servidors del monarca s'haguessin desplaçat fins a Barcelona, Castella, Toulousse o Sevilla, per efectuar les compres necessàries per a dotar sumptuosament l'ambaixada que organitzava, ens indica que fóra possible pensar que Consolí es trobava a Saragossa, on li fou encarregat l'encenser ${ }^{58}$.

\footnotetext{
${ }^{56}$ Per exemple, en dos documents pertanyents al mes de febrer de 1384 es constata la compra de cinc draps d'or a Saragossa per a Carles II de Navarra, així com diferents quantitats d'espècies. Vegeu J.R. CASTRO, Catálogo del Archivo. ob. cit., XV (1956), p. 29. doc. 58 i pp. 43-44. doc. 90, respectivament. Més endavant. el març de 1387. s'ordena el pagament a Samuel Amarillo, jueu, per preu de certs draps. joies, perles i espècies portades des de Saragossa per I. Infant Carles. la Duquessa de Bretanya i Leonel, fill bastard de Carles II. i el maig del mateix any veiem el mateix jueu en relació amb certa vaixella d'argent daurat $i$ esmaltat. draps i altres objectes, que porta de Saragossa a Pamplona per a la cort navarresa. Vegeu id. cit., vol. XVI. p. 322, doc. 778 i pp. 383-384. doc. 924. S. Andrés Valero afirma. respecte de la vinculació comercial Navarra-Saragossa que "Zaragoza aparece como una entidad de primer orden en el aspecto comercial con la corona navarra. siendo la que cubre la mayoria de las apetencias reales, acaparando las órdenes de compras frente a los países circunvecinos... Zaragoza tiene para la corona navarra un carácter de mercado internacional". Vegeu S. ANDRÉS VALERO. Relaciones comerciales de Zaragoza con la monarquía navarra en la Baja Edad Media. "Aragón en la Edad Media", X-XI (1993), pp. 31-37. esp. p. 32.

${ }^{57} \mathrm{El} 27$ de març de 1397 Carles III ordena el pagament de 27 florins a Robert el Beiner per preu de 7 estoigs de cuir "collado" per a guardar el seu pitxer d'or, dos canelobres d'argent, dos grans platers rentamans, el "drageur" nou rodó, l'encenser de la capella, la naveta de l'encens $i$ la "selda" de l'aigua beneita $i$ per un altre estoig per guardar-hi dos grans platers d'argent daurat (XXII, 1958, p. 166, doc. 365); el 4 d'abril següent el monarca ordena el pagament de certes quantitats de moneda a Enecot de Villava, argenter, per preu dels adobs de diversos pitxers. aigüeres i una copa (XXII, 1958, p. 181. doc. 403): el 19 d'abril següent es pagaven novament certes quantitats a Johan Garuain, argenter, per una copa d'or i per els guarniments d'uns esperons del rei. del collar d'un gos. de quatre planxes d'un mantell del rei i d'un fermall amb un gran balaix (XXII. 1958, pp. 195-196. doc. 435).

${ }^{58}$ Aquesta via d'investigació resta oberta a l'espera de noves informacions que puguin ajudar a establir exactament la vinculació de Blanch amb la cort navarresa. Tot $i$ així, novament és $S$. Andrés Valero qui en part tendeix cap a aquesta hipòtesi: "A pesar de los apuros económicos que la monarquía navarra suele atravesar. las joyerias de Zaragoza son visitadas asiduamente por los funcionarios navarros con encargo de comprar copas de plata, aguamaniles, vasos dorados con esmaltes en el fondo y sobrecubierta con esmaltes y serpientes, aiguiere de plata dorada a manera de frenillo con diversas serpientes". Vegeu S. ANDRÉS VALERO. ob. cit., pp. 36-37.
} 


\section{L'ARGENTER, AL SERVEI DE MARTÍ L'HUMÀ}

Ara com ara, els darrers testimonis de l'activitat de Consolí Blanch ens retornen a la cort catalano-aragonesa. Si la notícia més antiga que ens donava a conèixer l'existència d'un argenter estrasburguès anomenat Consolí Blanch el posava en relació amb l'Infant En Martí per al qual confeccionava un segell l'any 1372, les últimes empremtes de la trajectòria de l'alemany el vinculen novament amb Martí l'Humà i Maria de Luna, el casament dels quals es celebrà a Barcelona justament el mateix any 1372. Més enllà d'aquestes coincidències - que potser en el futur podran considerar-se menys casuals del que ara semblen-, en endavant la producció de Consolí sembla basar-se estrictament en la manufactura de matrius de segells. L'abril de 1399 cobrava 78 sous 3 diners jaquesos per preu d'un segell d'argent que el Senyor Rei En Martí li havia fet fer per a l'ofici dels oïdors de la cort, segons un albarà escrit el 26 d'abril de $1399^{59}$.

Una missiva redactada per Maria de Luna a Barcelona el 5 de novembre de 1400 assenyala l'obratge d'uns segells per a ella que ja devien estar acabats, per tal com fou donada l'ordre de retribuir Jacme Pastor, General Rebedor i Administrador de les monedes pertanyents a la Senyora Reina, amb 50 sous barcelonesos per preu de 3 florins de Florència que ell comprà i que donà a Consolí Blanch per daurar els esmentats segells. El pagament es féu efectiu durant el primer semestre de $1401^{60}$.

\footnotetext{
"ACA, RP, reg. 794. fol. LXXXVI v. Vegeu apèndix, doc. VII.

${ }^{(0)}$ F. de Sagarra posava aquesta noticia en relació amb una carta escrita a Saragossa el 14 d'octubre de 1399, en la qual s'ordenava el pagament de 7 sous jaquesos 35 florins d'or a Abraam Major, jueu i corredor de l'esmentada ciutat, per preu de 32 unces 1 quart 1 argenç d'argent que Maria de Luna li comprà amb l'objectiu de fer fer els seus segells. L'historiador es plantejava la possibilitat que aquests segells que es devien començar a obrar amb posterioritat al 14 d'octubre de 1399 fossin els mateixos que gairebé un any més tard, a partir del 5 de novembre de 1400, degué daurar Consoli Blanch. Aquest fet el dugué a suggerir la hipòtesi que els segells també haguessin estat realitzats per l'argenter estrasburguès. Aquest raonament no resulta del tot desencertat, especialment si hom recorda la noticia dels segells que Consolí havia deixat inacabats $i$ que un any més tard el Cerimoniós li exigia enllestir-los. Vegeu F. DE SAGARRA, ol). cit., p. 84.
} 
El període força dilatat en què podem resseguir la trajectòria professional de Consolí Blanch ofereix la possibilitat de conèixer de prop un dels argenters sens dubte més importants dels que desenvoluparen el seu art a la fi del segle XIV en l'àmbit de la Corona d'Aragó. El seu nom, però, roman en part a les fosques a causa de la mancança d'obres conservades que dificulta perfilar-ne la seva versatilitat, les característiques del seu dibuix i del modelat, les tonalitats d'esmalts utilitzades... No debades, un argenter estrasburguès que suposem ja format quan arriba a Barcelona havia d'esperonar amb el seu art les tendències de l'argenteria local, a través de noves pautes artístiques i nous mòduls figuratius.

Tampoc sabem quines foren les causes que portaren els membres de la cort reial aragonesa a conèixer el mestre de fer segells alemany, ni els mòbils que conduïren Consolí Blanch fins a Saragossa per acabar treballant per a l'arquebisbe Lope Fernández de Luna. Certament és notòria la relació entre aquest i el Cerimoniós, doncs li fou conseller, home de confiança i més endavant canceller, de manera que no resulta estranya la possibilitat que el prelat hagués conegut en persona l'argenter o bé que n'hagués rebut excel-lents referències per part del monarca, com potser succeí també amb Pere Moragues. D'altra banda, el paper de Maria de Luna, esposa de Martí l'Humà i vinculada a nivell familiar amb l'arquebisbe, tampoc s'ha de perdre de vista per entendre aquests lligams. Nogensmenys, si partim de la base que els argenters que treballaven per a la monarquia devien ser els que reeixien millor en el seu mestratge, especialment si eren nomenats argenter de Casa del Senyor Rei o mestre del gravat i assajador de moneda, no ha de sorprendre que augmentés la seva fama i que d'altres institucions reclamessin els seus serveis, com la Seu de Lleida o la Corona de Navarra.

En tot cas, la compilació revisada de les notícies publicades i l'aportació de dades inèdites permeten dibuixar el perfil d'un personatge esmentat en diferents ocasions. Tot i que el treball s'ha d'aferrar a fredes informacions d'arxiu, que li donen un caràcter àrid i poc amè, hom no pot deixar de considerar que, posades en relació les unes amb les altres, donen noves perspectives del personatge dins del seu context social, evidenciant de retruc la seva dimensió artística. 


\section{APÈNDIX 1 \\ DOCUMENTS}

1373, abril 16. Barcelona.

Pere el Cerimoniós ordena a Berenguer de Codinachs, Mestre Racional de la Cort, que admeti en el compte de Jacme Conesa, protonotari, la quantitat per la qual comprà 16 marcs d'argent amb els que Consolí Blanc, argenter, havia de fer el segell de les taules o de la majestat.

ACA. Cancelleria, reg. 1355, fol. 172 v.

Petrus, et caetera. Ffideli consiliario et Magistro Rationali curie nostre, Berengario de Codinachs, salutem et gratiam. Cum fidelis prothonotarius noster, Jacobus Conesa, de nostri mandato verbotenus sibi facto emerit sexdecim marchas argenti pro conficiendis et fabricandis sigillis tabularum seu nostre regie magestatis, que de presente per Conchilium Blanch, argenterium, facimus fabricari, volumus vobisque dicimus et mandamus quatenus, conscito vobis de precio pro quo dictum argentum fuit emptum per appocam illius a quo fuit habitum et quod ipsum argentum traditum fuit dicto Conchilio per confessionem seu recognitionem ab ipso Conchilio factam publico instrumento quidquid apparuerit dictum prothonotarium pro inde exsolvisse, in eius computo admitatis, recuperando ab ipso prothonotario presentes et appochas antedictas.

Datum Barchinone, $X V I^{a}$ die aprilis anno a nativitate Domini millesimo $\mathrm{CCC}^{\circ} \mathrm{LXX}^{\circ}$ tercio. Visa Roma².

Dominus rex, mandavit mihi Bernardo Michaelis. Probatum.

\footnotetext{
'Agraeixo al Dr. Ignasi Baiges la supervisió del present apartat.

'Es tracta de Francesc Roma, doctor en lleis, conseller i vice-canceller del Senyor Rei.
} 
[1373, maig 1-1374, juliol 31].

Notament del compte donat per n'Huguet Cardona, Tresorer de Mata d'Armanyac, Duquessa de Girona, en el qual consta que remunerà a Consolí Blanch, argenter de Barcelona, per preu de tres segells que féu per a la dita Senyora.

ACA. RP, reg. 787. fol. XL r.

Berenguer Sartre, prothonotari de la Senyora Duquessa.

Ítem, appar per lo dit compte ${ }^{3}$, en CIII cartes que 1 dit n'Uguet Cardona donà e pagà a $n$ Consolí Blanch, argenter de Barchelona, per rahó de III segells que féu a ops de la cort de la dita Senyora, ço és, lo segell major e lo segell secret e lo contrasegell, los quals segells lo dit prothonotari atorga haver reebuts. E havi àpocha cobrada en lo dit compte, perquè a memòria és-li'n fet açí lo present notament.

Iposterior al 1373, desembre].

Pagament d'un albarà de 886 sous barcelonesos, escrit a València el dia 11 de desembre de 1373, a Consoli Blanch, argenter de Barcelona, per preu de tres segells per a la Senyora Duquessa.

ACA, RP. reg. 613, fol. CIII v.

Ítem, done a·n Consolí Blanch, argenter de Barchinona, ab letra de la Senyora Duquessa ab son segell major segellada, data en València a XI dies del mes de deembre de l'any MCCCLXXIII, los quals li eren deguts per III segells que féu d'argent obs de la dita Senyora. Çò és, lo segell major, lo segell secret e contrasegell e per argent e fahedures d'aquells, segons que·s conté en la dita letra, la qual

${ }^{3}$ Notaments trets del compte primer que n'Huguet Cardona, dispensser e batle general de la Senyora Duquessa, ha donat de la aminstració /sic/ dels dits officis de .I. any e .III. meses qui començaren lo primer dia del mes de maig de l'any .MCCCLXXIII. e finiren per tot lo derrer dia del mes de juyol de l'any .MCCCLXXIII., romanent lo dit offici en son poder lfol. XXXVII $\vee . /$. 
cobre ensemps ab àpocha feta en poder d'en Galceran d'Ortigues, notari, a XXI de juny del dit any,...DCCCLXXXVI sous barchinonesos.

lal marge esquerre: Manament ab letra de la dita Senyora Duquessa. E àpocha. E àpocha [sic] d'en Berenguer Sartre, prothonotari de la dita Senyora qui atorga haver reebuts los dits segells. E és-lus fet notament en lo. $\mathrm{XVIII}^{\circ}$. libre de notaments comuns en XL cartes/.

[1381, febrer, posterior a].

Pagament d'un albarà de 10 florins d'or, expedit a Saragossa el 13 de febrer de 1381, a Concili Blanch, argenter d'Alemanya, segons manà donar-li graciosament el Senyor Rei.

ACA, RP, reg. 374, fol. 7 v.

Ítem, done $a \cdot n$ Concilí Blanch, argenter d'Alamanya, ab albarà d'escrivà de ració scrit en Saragoça a XIII dies del mes de ffebrer de l'any present MCCCXXXI, los quals lo Senyor Rey li mana donar graciosament, segons que en lo dit albarà se conté que cobre, $\mathrm{X}$ florins $\mathrm{d}$ 'or.

V

1382, juliol 30. Alzira.

Lletra del Cerimoniós dirigida a Domingo Pons, a qui li prega de donar resposta a la sol-licitud que el monarca li efectuà en relació a l'acceptació en el seu col-legi del fill de Cossolí de Casa Nostra.

ACA, Cancelleria, reg. 1274, fol. $133 \mathrm{r}$.

Lo Rey.

A $\cdot n$ Domingo Pons. L'altre jorn vos escrivim que donassets loch que son fill d'en Cossolí de Casa Nostra fos un d'aquells studiants als quals vós fets donar certa provisió per amor de Déu e per tal que puguen apendre. E neguna resposta de vós no havem hauda. Perquè us pregam altra vegada que ns façats saber vostre enteniment d'açò que·ns volets fer, de guisa que 1 dit Cossolí sapia per Nós si son 
fill porà haver per aquesta via bon recapte, ço que no li·n calega cercar altra, sabents que si li dats aquest loch, que-ns en farets gran plaer.

Dada en Algecira, sots nostre segell secret, a XXX dies de juliol de l'any MCCCLXXXII. Rex Petrus.

1383, octubre 9. Montsó.

Lletra de Pere el Cerimoniós dirigida al Capítol de la Seu de Lleida, al qual prega que deixin anar Mestre Consoli, argenter, a la seva cort.

ACA, Cancelleria, reg. 1281, fol. 131 v.

Lo Rey.

Nós per alguns affés havem ací necesari Maestre Consolí. E per aquesta raó li escrivim ab altra letra que tantost vinga a Nós, perquè us pregam e volem que 1 licenciets de venir, con sens vostra licencia fer no u pugués bonament, segons havem entès. Dada en Montsó, sots nostre segell secret, a .IX. dies d'octubre de l'any .MCCCLXXXIII. Rex Petrus.

Dirigitur Capitulo Ilerdense.

VII

[1399, abril].

Notament del pagament de 78 sous 3 diners jaccesos, a Consolí Albus, argenter de Casa del Senyor Rei, per preu d'un segell d'argent que el monarca li féu fer per a l'ofici dels oidors de la cort.

ACA, Reial Patrimoni, Mestre Racional, reg. 794, fol. LXXXVI r.-v.

Ramon ces Comes, prothonotari dessúsdit.

Ítem, appar per lo propdit libre de dates /segon libre de dates del compte d'en Ramon ces Comes, prothonotari e tinent los segells del Senyor Rei], en XLIX cartes. $\mathrm{E}$ per lo dit prothonotari foren donats e pagats a $\mathrm{n}$ Consolí Albus, argenter de Casa del Senyor Rey, per raó de I segell d'argent que de manament del dit Senyor fo fet a ops de l'offici dels oydors de la cort del dit Senyor, ço és, entre argent e trebayls 
de fer lo dit segell. E haví àpocha feta en poder d'en Berthomeu de Beses, notari, a XXVI dies d'abril de l'any MCCCXCIX, cobrada el dit compte e carta, LXXVIII sous III diners jaquesos. E axí a memòria és-li fet lo present notament que dege dar rahó del dit segell.

\section{Cronologia de Consolí Blanch ${ }^{1}$}

1372, octubre 13. Executa un segell secret per a l'Infant En Martí.

1373, abril 16. Efectua el segell de la majestat per al Cerimoniós.

1373, maig 1-1374, juny 21. Realitza els segells major, secret $i$ contrasegell per a Matha d'Armanyac.

1378, juliol 5. Ordre d'anar des de Saragossa a Barcelona per tal d'acabar el segell de la majestat per al Cerimoniós.

1379, febrer 6. Treballa a Saragossa sota l'empar de Francisco Aguilón, rector de l'església parroquial de Longares i alhora Rebedor dels Emoluments dels segells de l'Oficialat i del Vicariat.

1379, març 16. Treballa a Saragossa en una creu per a l'arquebisbe de la mateixa ciutat.

1379, abril 7. Rebuda de certa quantitat possiblement pel motiu anteriorment citat.

1379, abril 13. Rebuda de certa quantitat de monedes per utilitzar en l'obratge del peu de l'esmentada creu.

1379, abril 19. Rebuda de certa quantitat d'or pel motiu anteriorment citat.

1379, juny 16. Rebuda de certa quantitat de monedes pel motiu anteriorment citat.

1379, agost 3. Rebuda de certa quantitat de monedes per obrar els esmalts de l'esmentada creu.

1379, agost 13. Rebuda de certa quantitat de monedes per obrar els esmalts de l'esmentada creu.

1379, setembre 13. Rebuda de quatre pedres precioses per a col·locar a la mateixa creu.

1379, setembre 30. Rebuda de diverses pedres precioses per a col-locar a la mateixa creu.

1380, febrer 12. Pren com a aprenent a Joan de Chaumont.

1380, maig 8. Concessió graciosa de 50 florins d'or per els treballs efectuats en un segell secret per al Cerimoniós.

1381, febrer 13. Concessió graciosa del Cerimoniós de 10 florins d'or.

\footnotetext{
'Ateses les nombroses notícies a les quals s'ha anat fent referència al llarg de l'article, se n'ofereixen els resums de manera molt escueta i esquemàtica, amb l'objectiu de tenir una visió de conjunt de la trajectòria de Consolí Blanch. Les notícies inèdites s'indiquen amb cursiva.
} 
1381, juny 3. Realitza els anells d'argent que Sibil ·la de Fortià oferí a la Veracreu.

1381, novembre 15. Obra el bust d'argent de la Mare de Déu que Sibil la de Fortià entrega a Santa Engràcia de Saragossa.

1381, agost 1-octubre 31. Pagament de la quitació ordinària per part de la cort del Cerimoniós.

1382, abril 2. El Cerimoniós ordena que sigui Consolí Blanch qui executi la custòdia d'argent per a la Seu de Tortosa.

1382, maig 23. El Cerimoniós nomena Consolí Blanch mestre del gravat i assajador de les monedes d'or i d'argent que es batin a Saragossa i a tot el regne d'Aragó.

1382, juliol 30. El Cerimoniós busca allotjament a Lleida per al fill de Consolí, el qual hi vol estudiar.

1382, desembre 18. El Cerimoniós recomana a Nicolau Blanch, estudiant de la ciutat de Lleida, als bisbe i Capítol de la Seu d'aquesta ciutat per a ocupar un benifet vacant.

1383, octubre 9. El Cerimoniós reclama la vinguda a la cort de Consolí Blanch, el qual es troba a Lleida.

1383, octubre 9. El Cerimoniós demana al Capítol de la Seu de Lleida que permeti a Consoli anar a la cort.

1383, novembre 1-1384, gener 31. Treballa contínuament a la cort del Cerimoniós.

1384, febrer 1-abril, 30. Treballa contínuament a la cort del Cerimoniós.

1384, maig 1-juliol, 31. Rebuda de diversos pagaments de quitacions ordinaries per part de la cort del Cerimoniós.

1384, juliol 23. El Cerimoniós defensa la causa de Consolí davant el vicari de Lleida.

1384, febrer 1-abril 30. Treballa per a la cort del Cerimoniós durant tot el trimestre sencer.

1384, agost. Pagament de la quitació ordinària corresponent al trimestre anteriorment citat per part de la cort del Cerimoniós.

1384, juliol 31-maig 1. Treballa per a la cort del Cerimoniós durant tot el trimestre sencer.

1384, octubre. Pagament de la quitació ordinària corresponent al trimestre citat anteriorment per part de la cort del Cerimoniós.

1385. Realitza dos segells de la majestat per Carles II de Navarra i un altre segell per l'alferes de Navarra Charles de Beaumont.

1386, març 4. Efectua un segell per a Carles II de Navarra.

1386, abril 13. Obra un anell per a l'Infant Carles de Navarra.

1386, abril 21. Rebuda de 30 lliures del Rebedor de les Muntanyes de Navarra.

1397, abril 7. Executa un encenser d'argent per a Carles III de Navarra.

1397, abril 20. Fa un encenser d'argent per a Carles III de Navarra. 
1399, abril (?). Realitza un segell per a l'ofici dels oïdors de la cort de Martí l'Humà.

1401 [gener 1-maig 31]. Daura els segells de Maria de Luna.

\section{RÉSUMÉ}

La présence de l'orfèvre Consolí Blanch, procédant de l'autrefois ville allemande de Strasbourg, est documentée dans la couronne d'Aragon depuis la dernière partie du XIVe siècle. Malgré l'absence d'oeuvres conservées fruit de son talent, les archives sont témoin de ses créations pour la cour de la catalogne et l'Aragon, por l'archevêque de Zaragoza Lope Fernández de Luna, por les sièges cathédrales de Lleida et Tortosa, ainsi que por les rois de Navarre. La révision des documents publiés et les contributions inédites du présent article constituent un rapprochement à la grandeur artistique de ce personnage.

\section{SUMMARY}

The presence of a silversmith called Consolí Blanch, who came from Strasbourg in the Germanic Empire, it's testified in the area of the Aragon Crown, in the last quarter of 14th century. Although his works are disappeared, archive documents inform us about his production for the Aragon royal court, the archbishop of Zaragoza Lope Fernández de Luna, chapters and bishops of Lleida and Tortosa, and finally for the kings of Navarra. This article offers the revision of published documentation and the analysis of new researches, becoming an approximation to the artistic grandeur of this master. 